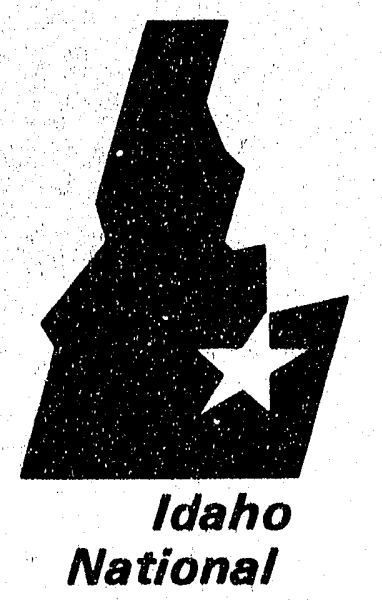

Engineering

Laboratory

\section{Managed}

by the U.S.

Department

of Energy
EGG-FSP- 10048

January 1992

CRYOGENIC SYSTEM OPERATING EXPERIENCE REVIEW FOR FUSION APPLICATIONS

L. C. Cadwallader

$$
\text { APR } 371992
$$


This docurrent contains new concepts or the author(s) interpretation of new calculations and/or measurements; accordingly, EG\&G ldaho, Inc. is required by the United States Government to include the following disclaimer:

\section{DISCLAIMER}

This report was prepared as an account of work sponsored by an agency of the United States Government. Neither the United States Government nor any agency thereot, nor any of their employees, makes any warranty, express or implied, or assumes any legal liability or responsibility for the accuracy, completeness, or usefulness of any information, apparatus, product or process disclosed, or represents that its use would not intringe privately owned rights. Feferences herein to any specific commercial product, process, or senvice by trade name, trademark, manufacturer, or othenwise, does not necessarily constitute or imply its endorsement, recommendation, or favoring by the United States Government or any agency thereof. The views and opinions of authors expressed herein do not necessarily state or reflect those of the United States Government or any agency thereot. 
EGG-FSP- -10048

DE92 012509

\title{
CRYOGENIC SYSTEM OPERATING EXPERIENCE REVIEW FOR FUSION APPLICATIONS
}

\author{
L. C. Cadwallader \\ Published January 1992 \\ Idaho National Engineering Laboratory \\ EG\&G Idaho, Inc. \\ Idaho Falls, ID 83415-3523 \\ Prepared for the \\ U.S. Department of Energy \\ Idaho Operations office \\ Under DOE Contract No. DE-AC07-76ID01570
}


This report was funded by the International Thermonuclear Experimental Reactor research and development task. The report is part of a series of reports on operating experience compilations from fusion experiments and similar technologies, such as particle accelerators, the chemical industry, and space exploration programs. The first report, EGG-FSP-9977, was on magnets. This report is a companion to the magnet report, since cryogenics are mainly used in fusion research as superconducting magnet coolant. The next planned report will be on vacuum systems. There are also two other reports on data analysis of actual tritium component operating experiences, EGG-FSP-8973 (a tritium waste treatment system) and EGG-FSP-9450 (tritium air monitors). The next planned report for tritium components will be on gloveboxes. 
This report presents a review of cryogenic system operating experiences, from particle accelerator, fusion experiment, space research, and other applications. Safety relevant operating experiences and accident information are discussed. Quantitative order-of-magnitude estimates of cryogenic component failure rates and accident initiating event frequencies are presented for use in risk assessment, reliability, and availability studies. Safety concerns with cryogenic systems are discussed, including ozone formation, effects of spills, and modeling spill behavior. This information should be useful to fusion system designers and safety analysts, such as the team working on the International Thermonuclear Experimental Reactor design. 


\section{EXECUTIVE SUMMARY}

This report outlines cryogenic system operating experiences and accident events for use by fusion system designers and safety analysts. Cryogenic liquids are used for tokamak vacuum systems, neutral beam vacuum systems, pellet injectors, and magnet coolant. Magnet coolant systems are the largest, with system capacities 10's of cubic meters of liquid helium, perhaps up to 80 cubic meters. The cryogenic system, or cryoplant, must be available for magnets to be operable. Therefore, events callsing downtime in the cryogenic system will affect the entire facility. This report discusses existing system operations, operational difficulties, major cryogenic accidents that have occurred, the use of field experience information from other industries to quantify component behavior, and presents what information can be learned from safety work from other industries that use cryogens. Learning from other industry experiences enhances design processes and safety, and insures a higher level of practical completeness in facility risk assessment.

The largest problems with system operations are related both to design and to operations/maintenance personnel. The largest design problem is properly calculating heat inleakage to the system. This is very difficult when one considers that the system may not be constructed exactly as shown on the drawings. System operations personnel from several operating facilities suggest oversizing the cryoplant, by $20 \%$ to $50 \%$, even up to $100 \%$ excess capacity, to account for variations in heat inleakage. While additiunal capacity is expensive, the consequences of not being able to operate the machine surely outweigh the cryogenic system construction and operating costs.

The largest operations problem is inleakage of gases into the sysiems, causing freeze plugging and heat inleakage through the vacuum insulation. Building and maintaining a leak-tight system is not a trivial matter. 'Cold leaks' have occurred in most systems; that is, systems that are leak-free at room temperature develop small leaks when cooled to cryogenic temperatures. Even if future cryogenic systems are housed in helium or nitrogen atmospheres (less neutron activation than with an air atmosphere), inleakage gases will still present heat inleakage and freeze plugging concerns. 
Cryogenic accidents have occurred in space programs, the chemical industry, and accelerator research. I found one citation of 3 suffocation fatalities from a nitrogen gas cloud, and one air separation plant event where five workers nearly suffocated from nitrogen exposure. Significant releases of cryogens have occurred in the US, greater than $2,000 \mathrm{~m}^{3}$ of liquid oxygen from a space program storage tank, and releases up to 120 metric tons of ammonia from chemical plants. There have been many small public evacuations from the vicinity of US chemical plants, with some of these due to cryogenic gas (1iquefied natural gas, liquefied petroleum gas, ammonia, etc.) releases. Such large releases cannot be overlooked for future fusion facilities, where several cubic meters of reserve liquid helium and liquid nitrogen will be stored for system startup cooldowns and possible magnet quench recoveries.

Large releases of cryogenic fluids pose several concerns. First, the confinement building may be at risk because of the effects of cold gas intrusion. The building pressure will drop by several $10^{\prime} \mathrm{s}$ of $\mathrm{kPa}$ in a few minutes, then increase to several $10^{\prime} \mathrm{s}$ of $\mathrm{KPa}$ overpressure as the cryogenic gas warms over the next hour. Therefore, confinement building seals and penetrations that normally experience only slight underpressures will be exposed to large pressure variations in relatively short time frames. The next concern is that cryogenic gas releases form a 'pancake cloud' shape that is characteristic of denser-than-air releases, and plant workers are at risk. Also, any radioactive isotopes entrained in the cloud (tritium, activated air, activated dusts, etc.) will produce higher doses at the site bounclary, at least until the cloud warms and disperses perhaps in a matter of minutes, unless the release is sustained over a long time period. Of course, activated aerosols may not be entrained in the cold gas cloud because of plateout on cold surfaces in the building, but since the fission industry has not been able to adopt a workable guideline for fission product plateout, it is unlikely that fusion safety work will be able to do so in the near future. Another effect of a large release is that the fusion magnets may be damaged, either structurally or by electric arcing when the cryogenic system is breached, allowing cryogen phase change. The final problem with large releases is one of public relations, which may threaten premature shutdown rather than speedy repairs. 
I have taken cryogenic system component failure rates and initiating event frequency values from the literature on cryogenic systems and reviewed them for applicability to fusion systems. The results are given in the last two chapters of this report, and the failure rates are given in Table S-1 as well as in the text. The most notable difference from past practices is in the use of failure rates for cryogenic piping. Past work has typically used fission reactor derived failure piping rates for application to cryogenic piping. This is because the fission industry has compiled the best data sets. However, cryogenic piping is designed to be thin walled to reduce conduction heat transfer down the length of the pipe from the heat source (in our case, the magnets) to the rest of the system. Cryogenic piping can be 2 to 4 times thinner walled than fission reactor piping, and cryogenic piping is never clad with another material. Using a liquefied natural gas data base, I found that cryogenic piping failure rates were over a factor of 1000 higher than those for fission reactor piping. Fortunately, cryogenic piping runs are usually short, so there should not be too much effect in the risk profile from this suggested new failure rate. Cryogenic piping is also at risk from earthquakes, since it is thin walled and may not be able to carry seismic-induced stresses as well as the thicker walled fission reactor piping. 
TABLE S-1. SUMMARY OF ORDER-OF-MAGNITUDE FAILURE RATES FOR CRYOGENIC SYSTEM COMPONENTS APPLICABLE TO FUSION FACILITIES

Component Description

Small reciprocating compressor

a11 failure modes

Large reciprocating compressor

all failure modes

$5 \mathrm{~F}-05 /$ hour

100

Large turbo-compressor

all failure modes

Sma11, diry reciprocating gas expander
all failure modes

Sma11, wet reciprocating expander

all tailure modes

Axial flow turbo-compressor

all failure modes

Plate and fin heat exchanger

major failures (breach)

minor failures (leakage)

Motor-operated valve (all sizes)

fails to operate on demand

plugging

external rupture

leak past the seat

freezing up in position

Air-operated valve (all sizes)

fails to operate on demand

plugging

$3 E-04 /$ demand

$1 E-04 /$ demand

$6 \mathrm{E}-07 /$ hour

$3 E-03 /$ hour
$3 E-04 /$ hour

3

10

$2 E-04 /$ hour

5E-05/hour

10

$6 E-06 /$ hour

100

1E-05/hour

100

1E-03/demand 3

1E-04/demand 3

$6 \mathrm{E}-07 /$ hour $\quad 5$

$3 E-03 /$ hour $\quad 5$

$6 E .07 /$ hour $\quad 100$ external rupture

leak past the seat

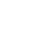

* note: The error factor is defined here as the upper bound/average value 
TABLE S-1. SUMMARY OF ORDER-OF-MAGNITUDE FAILURE RATES FOR CRYOGENIC SYSTEM COMPONENTS APPLICABLE TO FUSION FACILITIES (Continued) Component Description

Failure Rate Error Factor

Pressure relief valve (a11 sizes)

fail to open on demand

$1 \mathrm{E}-02 /$ demand 5

external rupture

$6 \mathrm{E}-07 /$ hour

premature opening

1 E-05/hour

Motor-driven centrifugal pump (al1 sizes)

fail to continue to run

$3 \mathrm{E}-04 /$ hour

100

fail to start on demand

$3 E-03 /$ demand

fail to run at rated speed

$2 E-05 /$ hour

100

external breach failure

1 E-09/hour

30

Large cryogenic storage tank breach

$1 E-06 /$ year

Liquid level sensor

incorrect output

no output

erratic indication

$2 E-03 /$ hour

2

$6 E-04 /$ hour

2

$4 E-05 /$ hour

2

Pressure transducer

low output

$8 \mathrm{E}-03 /$ hour

2

high output

$7 E-03 /$ hour

2

erratic output

$6 \mathrm{E}-03 /$ hour

2

external leakage

$7 E-04 /$ hour

2

Venturi flow meter, all modes

1E-05/hour

10

Silicon diode temperature detector

all failure modes

1E-05/hou"

10

Cold cathode vacuum gauge

all failure modes

1E-07/hour

10

Steel gas cylinder breach

1E-02/year

8 
TABLE S-1. SUMMARY OF ORDER-OF-MAGNITUDE FAILURE RATES FOR CRYOGENIC SYSTEM COMPONENTS APPLICABLE TO FUSION FACILITIES (Cont inued) Component Description Failure Rate Error Factor.

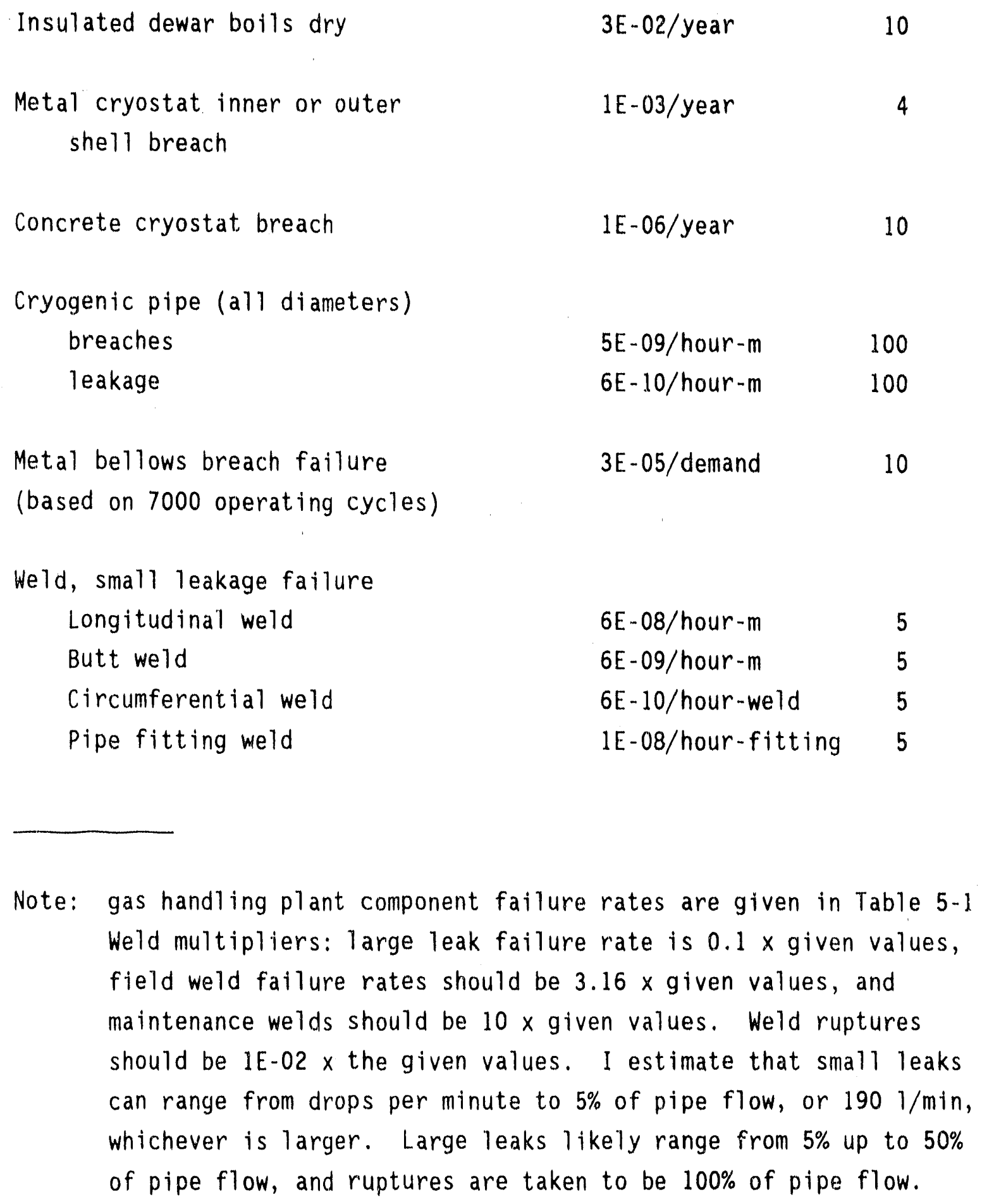

Note: gas handling plant component failure rates are given in Table 5-1 Weld multipliers: large leak failure rate is $0.1 \times$ given values, field weld fallure rates should be $3.16 \times$ given values, and maintenance welds should be $10 \times$ given values. Weld ruptures should be 1E-02 $x$ the given values. I estimate that small leaks can range from drops per minute to $5 \%$ of pipe flow, or $1901 / \mathrm{min}$, whichever is larger. Large leaks likely range from $5 \%$ up to $50 \%$ of pipe flow, and ruptures are taken to be $100 \%$ of pipe flow. 


\section{CONTENTS}

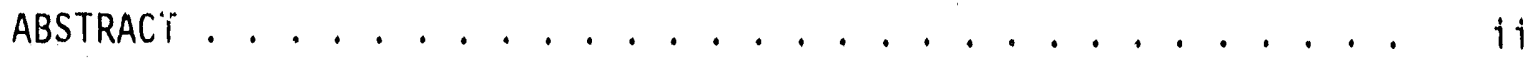

EXECUTIVE SUMMARY ....................... . ... iji

ACKNOWLEDGMENTS . . . . . . . . . . . . . . . . . . . . xi

NOMENCLATURE . . . . . . . . . . . . . . . . . . . . . xii

1. INTRODUCTION . . . . . . . . . . . . . . . . . . . 1-1

Chapter 1. References.................. 1-3

2. CRYOGENIC SYSTEM OPERATING EXPERIENCES . . . . . . . . . 2-1

2.1 Chapter Summary .. . . . . . . . . . . . . . . 2-1

2.2 Fusion Cryogenic System Operations . . . . . . . . 2-1

2.2.1 Large Coil Task Experiences . . . . . . . . . 2-2

2.2.2 T-15 Experiences................ 2-3

2.2.3 Tore Supra Experiences . . . . . . . . . . 2-4

2.2.4 TFTR Experiences.............. . 2-5

2.2.5 ORMAK Experiences . . . . . . . . . . . . . 2-6

2.3 Particle Accelerator Cryogenic System Operations . . . 2-7

2.3.1 Fermilab Experiences . . . . . . . . . . . 2-7

2.3.2 Intersecting Storage Rings Experiences..... . 2-9

2.3.3 MSU Cyclotron Experiences . . . . . . . . . 2-9

2.4 Superconducting Magnet Energy Storage Cryogenic

System Operations . . . . . . . . . . . . . 2-10

2.5 Medical Technology Magnet Cooling System Operations . . 2-11

Chapter 2. References .............. 2-15

3. SUMMARY OF ACCIDENTS IN CRYOGENIC SYSTEM OPERATIONS . . . . 3-1

3.1 Chapter Summary . . . . . . . . . . . . . . . . . . 3-1

3.2 Cryogenic Accidents in US Government Operations . . . . . 3-2

3.3 Cryogenic Accidents in the Chemical Industry . . . . 3-8

3.4 Ozone Explosion Events .. . . . . . . . . . . 3-10

3.5 Fires in Facilities that Use Cryogenic Fluids. . . . . . 3-15 
3.6 Large Storage Tank Accidents . . . . . . . . . 3-16

3.7 Selected Human Error Events Involving Fusion

Cryogenic Systems ............. 3-18

3.8 Incidents with Small Cryogenic Containers ..... 3-18

3.9 Conclusions . . . . . . . . . . . . . . . 3-19

Chapter 3. References ............. 3-21

4. POTENTIAL SAFETY CONCERNS WITH CRYOGENIC FLUIDS ...... . 4-1

4.1 Introduction to Potential Safety Concerns with Cryogenic Fluids ............... 4-1

4.2 Dielectric Breakdown Through Cryogenic Gases . . . . 4-2

4.3 Cunfinement Building Pressure Responses to Large Cryogen Spills ............... 4-. 4

4.4 Effects of Cold Temperatures on Surrounding Structures ........... 4-5

4.5 Cryogen Contamination Concerns . . . . . . . 4-6

4.6 Modelling Large Cryogen Spills to the Environment . . . 4-8

4.7 Gas Handling Plant Safety ............ . 4-9

4.6 Noise Protection for Cryogenic Systems ...... 4-10

4.9 Cryogenic Safety Issues to Examine for

Future Facilities............ 4- 4-10

Chapter 4. References.............. 4-11

5. SUGGESTED FAILURE RATES FOR CRYOGENIC COMPONENTS ..... . 5-1

5.1 Cryogenic Compressors ............ 5-6

5.2 Cryogenic Piping ............ . . . 5-7

5.3 Expansion Engines........... 5- . . . . . .

5.4 Heat Exchangers ............... 5-11

5.5 Cryogenic Valves ............. 5-11

5.6 Cryogenic Pumps.............. 5- . . . . . . . .

5.7 Pressurized Cryogenic Liquid Storage Tanks ...... 5-13

5.8 Cryogenic Instrumentation . . . . . . . 5-13

5.9 Gas Handling Plant Equipment ......... 5-14

5.10 Unpressurized Storage Containers ........ 5-15

Chapter 5. References............ 5-22 
6. CRYOGENIC SYSTEM INITIATING EVENTS FOR FUSION FACILITIES . . . 6-1

Chapter 6. References ................ 6-6

\section{TABLES}

2-1. Magnetic resonance imaging cryogenic events . . . . . 2-12

2-2. Summary of operations problems encountered in liquid helium and liquid nitrogen systems .......... 2-14

3-1. Cryogenic events from U. S. Department of Energy operations .................... . 3-4

3-2. Ozone explosion events from liquid nitrogen irradiation . 3-12

3-3. Summary of types of cryogenic accidents, incidents, and events ................. . . 3-20

5-1. Warm gas handling plant order-of-magnitude component failure rates applicable to fusion facilities...... 5-16

5-2. Summary of order-of-magnitude failure rates for cryogenic system components applicable to fusion facilities... . 5-18

5-3. Typical hands-on cumponent repair times for cryogenic components with applicability to fusion facilities . . 5-21

6-1. Cryogenic system initiating event frequencies from various industries applicable to fusion........ . 6-2

\section{FIGURES}

1-1. Liquid helium system schematic diagram............ 1-2

5-1. The reliability bathtub curve . . . . . . . . . . . . 5-2 


\section{ACKNOWLEDGMENTS}

I want to thank the reviewers, particularly Bob Fleming and Mike Marchlik at Princeton for their technical review. Of course, the conclusions are my own. Steve Piet and Doug Holland in Idaho gave significant time to review the total report. I would also like to thank the library staff for their time and effort to help collect all of the reference materials necessary for this document. The data collection task was both broad and seemingly endless. International Thermonuclear Experimental Reactor Safety and Environment task funding made this work possible. 


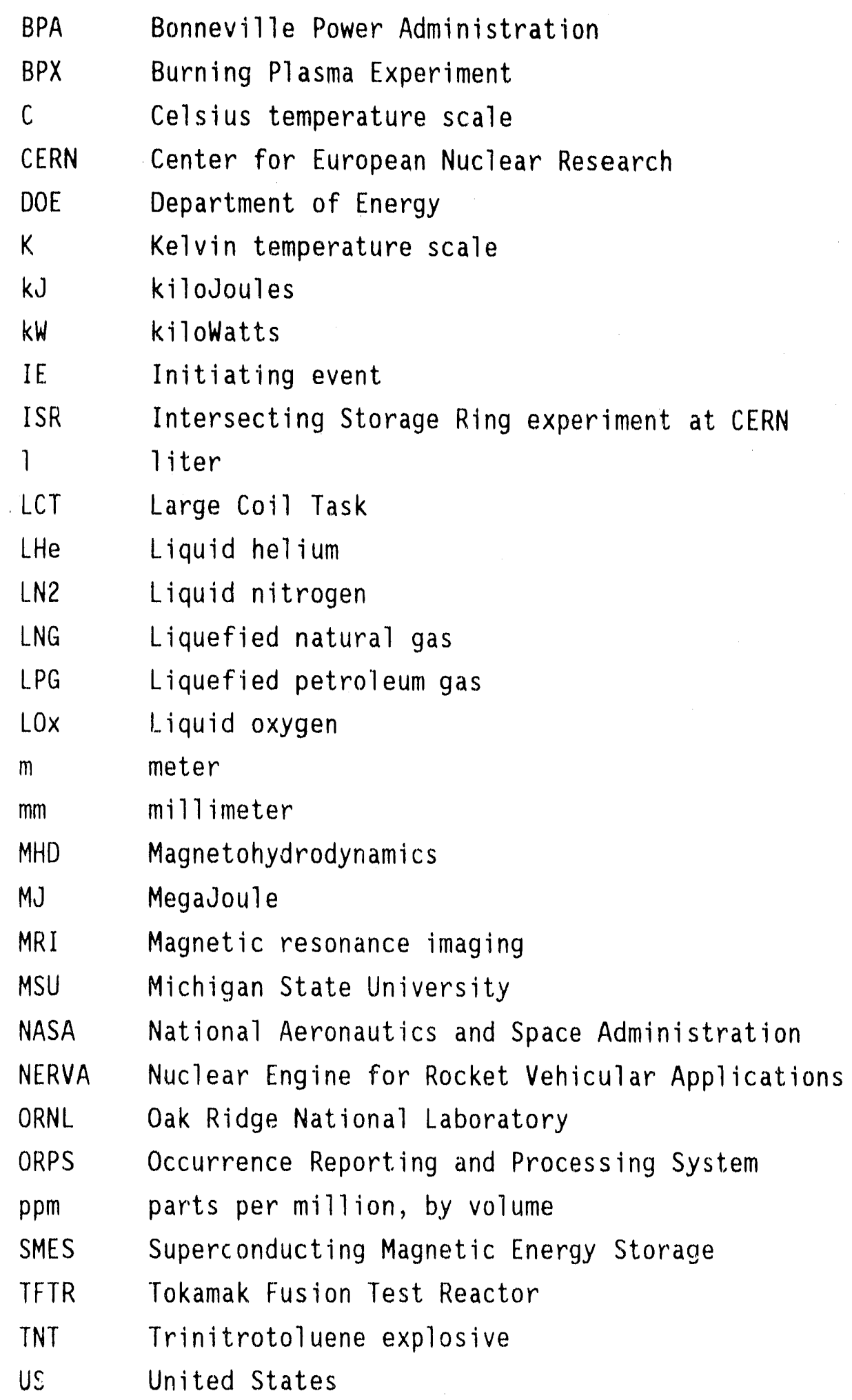




\section{CRYOGENIC SYSTEM OPERATING EXPERIENCE REVIEW FOR FUSION APPLICATIONS}

\section{Introduction}

This report outlines cryogenic system operating experiences for use by fusion system designers and safety analysts. Cryogenic liquids are used for tokamak vacuum systems, neutral beam vacuum systems, pellet injectors, and magne: coolant. Magnet coolant systems are the largest, using system capacities of $10^{\prime} \mathrm{s}$ of cubic meters of liquid helium. Vacuum systems will use much less than that, pellet injectors will use on the order of hundreds of liters, and there are likely to be a few radiation detectors that will use tens of 1iters. A simplified cryogenic system schematic diagram for a particle accelerator facility magnet coolant system is given for reference in Figure 1-1.1-1 The cryogenic system, or cryoplant, must be available for magnets to be operable. Therefore, events causing downtime in the cryogenic system will affect the entire facility. This report discusses existing system operations, operational difficulties, major cryogenic accidents that have occurred, the use of field experience information to quantify system behavior, and presents what information can be learned from safety work for other industries that use cryogens. Learning from experiences from other industries erihances design and safety, and insures a higher level of practical completeness in facility risk assessment.

This report is structured in order of: operations problems, including downtimes for some operational difficulties; large scale accidents involving large releases, fatalities, or major system component replacement; cryogenic safety concerns that must be treated for future fusion facilities; field experience and estimated failure rates for cryogenic components; and initiating event frequencies from fusion and other industries that are applicable to future fusion safety work.

Even though vacuum is employed as an insulation barrier for heat transfer in cryogenic systems, I have not addressed vacuum pump safety concerns or reliability in this report. In the future, I will write another report similar to this one, for vacuum systems. That report will include mechanical pump, turbomolecular pump, and cryopump operating experiences, and vacuum safety concerns. 


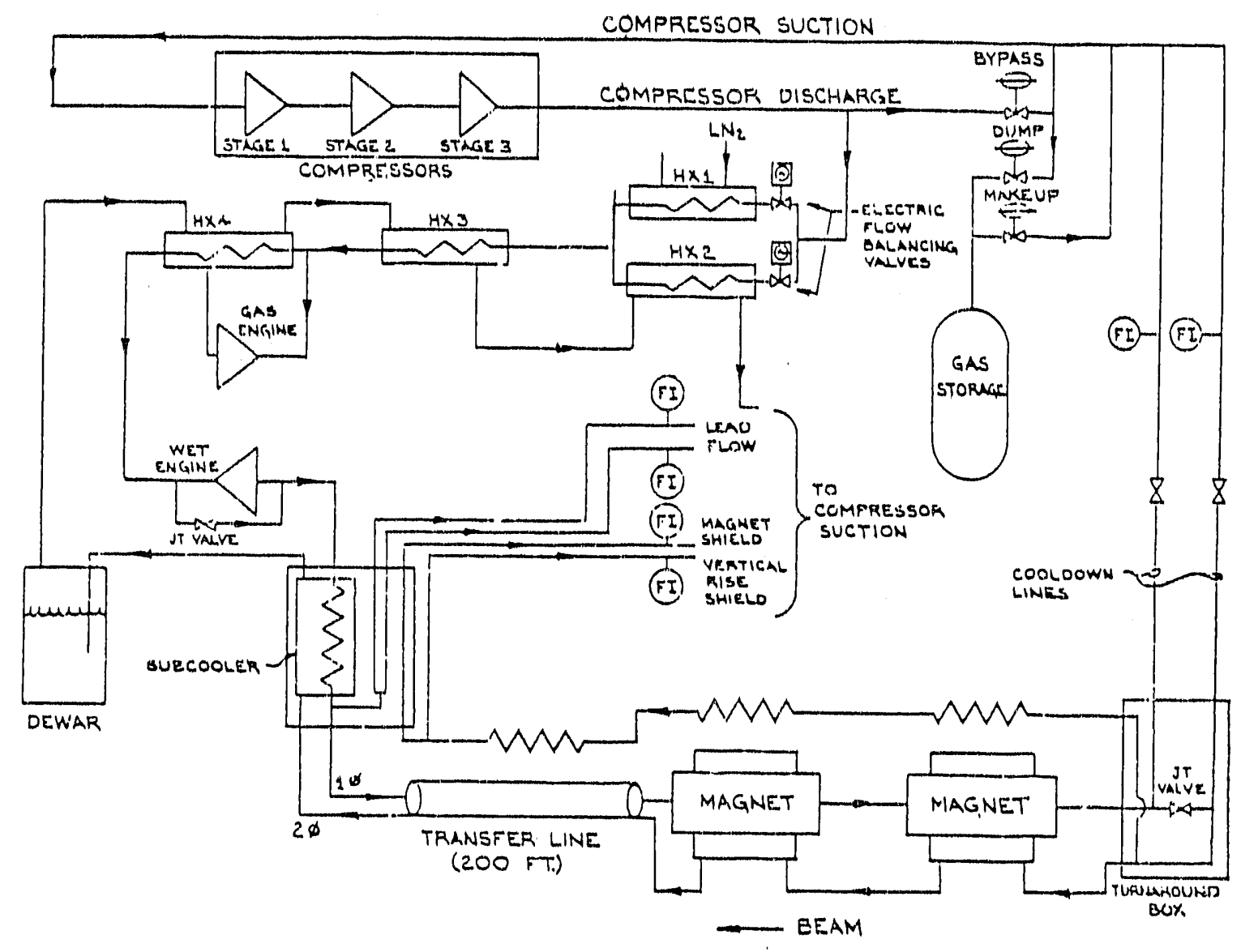

Note: FI stands for flow indicator

$H X$ stands for heat exchanger

JT stands for Joule-Thompson expansion valve

LN2 stands for liquid nitrogen

(figure taken from reference 1-1)

Figure 1-1. Liquid helium system schematic diagram. 


\section{Chapter 1. References}

1-1. R. A. Andrews et a1., "Heilium Refrigeration System and Cryogenic System for Superconducting Switchyard Magnets at Fermilab, "IEEE Transactions on Nuclear Science, NS-26, June 1979, pages 4093-4095. 


\section{Cryogenic System Coperating Experiences}

This chapter contains discussions of cryagenic system operating experiences from fusion experiments and superconducting magnet systems, such as: superconducting magnet energy storage (SMES) systems, medical technology, and cryogenic magnetohydrodynamic (MHD) devices.

\subsection{Chapter Summary}

In general, most cryogenic systems have experienced small cryogen leaks to the atmosphere or the butlding, and air leakage into the system. Condensation from water vapor in the air and even the freezing of nitrogen and oxygen from air onto cold piping has been an operations concern. cryogenic components, such as pumps and valves, have failed and week-long shutdowns for entry into cold boxer have been necessary for several of the systems discussed here. Impurity $g$ ses and pump/compressor lubricating oils in the system have hampered proper operations. The Tokamak Fusion Test Reactor (TFTR), Tore Supra tokamak, and TEVATRON accelerator expertences are among the most insightful discussed here. The operating experience literature recommends extra system cooling capacity, from $20 \%$ to $50 \%$ and up to values as high as $100 \%$, to negate problems with heat inleakage in as-built systems. Heat inleakage is difficult to calculate, especially after the inevitable variations introduced in the construction phase. In this chapter, I discuss some cryogenic system experiences from fusion, particle accelerators, medical technology superconducting magnets, and a superconducting magnetic energy storage (SMES) unit. Large accidents involving cryogens are discussed in the next chapter.

\subsection{Fusion Cryogenic System Operations}

Fusion operating experiences are widely varied. Some systems have worked well and others have been a continual source of operational problems. This section contains discussions of several fusion experiment experiences with cryogenic systems, including the Large Coil Task (LCT), Tore Supra, and the Tokamak Fusion Test Reactor (TFTR). 


\subsubsection{Large Coil Task Experiences. Typical problems with cryogenic}

systems have been found at the Large coil Task (LCT) experiment at 0ak Ridge National Laboratory (ORNL), which was used to test helium superconducting toroidal field magnet coil concepts for fusion applications. Designers stated that the helium refrigerator system was initially undersized, mainly due to economic reasons. The refrigerator could not supply enough liquid helium to meet the demand during some phases of operation, such as the high-current multi-coil tests, where the forced helium boiloff exceeded the cryoplant's rate of production. An accumulator storage tank and two small satellite systems were added to help reduce the impacts of these high demand operations. The system was accepted with this marginal cooling capability, but it presented problems throughout the life of the project. ${ }^{2-1}$ The undersized unit also led to operational delays, such as long times for cooling the magnets, usually on the order of one to two days, such as when electrical power was lost to the helium cooling system. Other difficulties caused even longer recovery times.

The LCT also uncovered several other issues related to cryogenic cooling systems. Several of the magnet coils had difficulty with helium leaks into the insulating vacuum jackets and air leaks into the system heat exchangers. To solve the helium leak problem into the liquid helium (LHe) dewar storage vacuum jackets, vacuum pumps were set up to continuously pump down the vacuum region. On one occasion, a mechanical pump stopped, and valving failed to prevent air flow into the vacuum jacket. The enhanced heat transfer from gas in the jacket boiled the dewar dry. Five days of repairs to the dewar consisted of repairing the pump, warming the dewar, and evacuating the vacuum jacket. In the time span of these repairs, the magnets warmed up to about $50 \mathrm{~K}$ and had to be recooled to continue operations. ${ }^{2-2}$ Future fusion experiments will probably be housed with nitrogen or helium atmospheres, rather than air, to limit neutron activation of the atmospheric gas and also to reduce chemical reaction concerns (such as graphite fires). These inert atmospheres also mitigate effects of electrical fires. Nonetheless, any warm (295 K) atmospheric gas inleakage would still present a problem of increased cryogenic system heat transfer. 
An LCT cold box heat exchanger plugged up shortly after operation began, due to air freezing in the cold heat exchanger. The air leakage into the heat exchanger was found to be through a faulty burst disk. ${ }^{2-?}$ The heat exchanger had to be replaced because of mechanical damage from the volume expansion of the frozen gases. ${ }^{2-3}$

Air leakage, or contamination, into the LCT system allowed nitrogen and oxygen to freeze in the helfum channels, accumulating up to tens of kilograms, especially for the pool boiling magnets. ${ }^{2-1}$ Air does not even have to leak into the machire to cause difficulties. Superconducting Tokamak T-7 experiences showed that ice buildup from atmospheric humidity onto the liquid nitrogen temperature vacuum vessel flanges caused extra stresses that led to small amounts of flange separation and consequently, air leakage into the piping. Thermal insulation was recommended to serve as a barrier against ice infiltration. ${ }^{2-4}$ Water vapor condensation buiiding up to form ice has been an operations problem for many cryogenic systems. A liquid nitrogen feedthrough tube, passing through a larger pipe in the insulation of a chamber, suffered a rupture due to ice buildup. Water vapor condensed on the outside of the liquid nitrogen tube, between the tube and the larger insulation pipe passageway. The ice built up to the point where the tube was compressed by the pressure of the annulus of ice around it. The liquid nitrogen flowing through the tube built up pressure at this constriction and caused the tube to rupture. ${ }^{2-5}$ Ideas to prevent this sort of event are to invert the insulation pipe, so moisture does not collect there, flush the annular area with dry gas to purge the moisture, or plug the opening with a sealant such as silicone. These fixes should be performed prior to high neutron flux operation.

\subsubsection{T-15 Experiences. Heat leakage into a cryogenic system is} difficult to calculate, so extra cooling capability must be designed for in fusion cryogenic systems. Accelerator experience tells us that refrigeration plant output is reasonably specific, but heat loads and the execution of design details about heat loads during construction have a greater chance for error. ${ }^{2-6}$ Another superconducting experiment, Tokamak T-15, experience shows this fact, since the heat flows from the pipelines into the magnet cases, also coupled with the problem that the 
1 iquefiers were not able to deliver rated capacity, prevented the machine from reaching lower than 12 to $8 \mathrm{~K} .{ }^{2-7}$ The design value for magnet

temperature was $4.5 \mathrm{~K}$. Even at 30 metric tons/hour flow rate through the tokamak, with one helium liquefier unit in the liquefying mode and one in the refrigerating mode, lower temperatures could not initially be reached.

2.2.3. Tore Supra Experiences. The superconducting tokamak Tore Supra has also had some difficulties with the magnet cryogenic cooling system. $^{2-8}$ some of Tore Supra's detrimental early experiences were excessive liquid helium consumption at rated temperature, reduced thermal shield effectiveness from expected design values, air inleakage through the safety relief valves, and water inleakage from compressor heat exchangers.

The Tore Supra cryogenic system has had later difficulties as well. 2-9 Over a time perfod of six months in the third year of operation, there were 18 machine outages due to faults in the magnet liquid helium cooling system, for a total downtime of 41 hours. This is an improvement over initial operations, because for the first two years of operation, the cryogenic system averaged one operational day (11 hours) of downtime per month, or 66 hours per half year. Past problems with the system included contaminants in the cold box, a ball bearing failure on one of the screw compressor motors, and clogged liquid helium filters. For a six month period that was closely surveyed, the general problems were in these areas:

Components (valves, gauges, etc.) 9 failures for 25 outage hours Computer control faults 3 failures for 8 outage hours Analyzers (oxygen monitors, etc.) 3 fallures for 3 outage hours Power outages 2 failures for 4 outage hours

Cloggings (filters, etc.) 1 failure for 1 outage hour Engines (compressors, pumps, etc.) o failures for 0 outage hours utilities (cooling water, etc.)

0 fallures for 0 outage hours

The paper also noted that summer thunderstorms, which have a tendency to cause losses of offsite power, added to the cryogenic system utilities' power outage downtime. The latter 6 months of the operating year at 
Tore Supra showed no cryogenic system problems that precluded normal facility operations. The staff attributed this increase in cryogenic system availability to more efficlent preventive maintenance practices that were implemented after closer system scrutiny. ${ }^{2-9}$

2.2.4 TFTR Expertences. The Tokamak Fusion Test Reactor (TFTR) uses a 1-kW refrigeration capacity liquid helluin system for their neutral beam injector cryopanels. Two years $(11,000$ hours) of operations experience with this systen has shown that there have been several types of problems. The system is bullt with redundancy in mind, such as a third helium compressor, several storage tanks for liquid helium, and a variety of redundant sensors. Startup problems included electrical control problems, compressor 011 and cooling water contamination, and process helium gas contamination The compressors shut down due to improper set points on the circult breakers, and on low 411 unt 11 the 011 supply system was replaced with a less complicated system. ${ }^{2-10}$

There have been other problems from the TFTR system as it matured. While the compressors and their motors hive operated we11, there has been vibration and mechanical fatigue in tubing that allowed two large compressor 011 leaks, which are both a fire hazard and a significant unavailability issue. Small leaks are also present - they are unsightly, but were not considered to pose a safety or availability concern. The compressor cooling water was inttially found to be contaminated with a variety of debris, including: weld slag, paper, cleaning rags, etc. A strainer was placed in the cooling water line, but in summer months the strainer became fouled with algae. The recurring algae plugging has caused shutdowns to clean the strainer. During the first wintertime shutdowr, freezing temperatures occurred and frozen compressor cooling water caused a flow control valve to burst. The compressor room is heated now for wintertime conditions. ${ }^{2-10}$

The TFTR cold box for temporary liquid helium storage has had several inishaps. A vacuum shell is used for cold box insulation. A single diffusion pump was initially used to maintain the vacuum, but there were multiple vacuum demands on the pump, so a spare mechanical pump was added to assure that the vacuum in the shell would be properly maintained. 
Later, the diffuston pump failed due to oil loss in a high throughput operation period. It was replaced with a turbomolecular vacuum pump. This turbomolecular pump was found to be defective. The system was shut down to replace $t$. Also, a brazed aluminum to stainless steel joint leaked, causing a shutdown for repair. Some of the primary units in the pairs of temperature sensor diodes have had fallures, so the redundant units are used for temperature readings. One diode well leaked helium gas, so the cold box had to be opened for repairs. This operation caused significant downtime for purging, warmup, and then cooldown after repatrs were completed. During replacement, a vacuum isolation valve drive mechanism failed to close its valve pruperly and air was admitted into the vacuum she $11 .{ }^{2-10}$

A faulty diode in the TFTR turboexpander power supply caused a shutdown, and a faulty optical link in the turbine speed circuit caused another shutdown. Over 30 system trips due to gas high impurities have occurred in two years of operation. These impurity trips average more than one per month over the operating period discussed. Even though these events seem frequent, the system is said to have performed well overall. Martin et a1. 2-9 thought complex cryogentc system startup was full of unexpected, unpleasant, costly, and downtime-intensive surprises. They did recommend that a 'safety factor' of $50 \%$ be included when sizing a moderate duty liquid heltum refrigeration system. ${ }^{2-10}$

\subsubsection{ORMAK Experiences. The ORMAK fusion experiment at ORNL has also} published some of their liquid nitrogen (LN2) magnet coolant system operating experiences. $2-11$ The magnet cooling system was thoroughly pressure tested, and weaknesses in the electrical ceramic insulators placed in the LN2 1 ines were discovered at $7.5 \mathrm{MPa}$. The insulator design was changed to withstand the $10 \mathrm{MPa}$ pressure test (the normal system operating pressure was $1.4 \mathrm{MPa}$ ). Helium leak testing also revealed that less than $1 \%$ of all controlled field brazes leaked. These brazes were reworked.?-11 Initial ORMAK shakedown operations revealed that several ball valves were delivered by the manufacturer with incorrect seals and seats. The original ultrasonic level sensors were faulty and were replaced with more reliable thermistor level sensors. The LN2 centrifugal pump seals were rated for 500 hours of operation, and several 
seal fallures at the 500 hour time caused the URMAK staff to replace the pump with a hermetically enclosed unit. ${ }^{2-12}$

\subsection{Particle Accelerator Cryogenic System Operations}

This section discusses Fermilab and TEVATRON operating experiences, and a brief discussion of the Intersecting Storage Ring and a university cyclotron.

2.3.1. Fermilab Experiences. Particle accelerators, and Fermilab in particular, began switching over from water-cooled magnets to liquid helium-cooled units in 1979. Some of the early prodlems with the liquid helium units at Fermilab were that oils from the compressors and expanders leaked into the helium stream, but could be removed from the helium down to 10 parts per billion. Liquid helium satellite untt (producing 95 liters/hour in the liquefying mode) reciprocating compressors converted from ammonia and freon service worked between 800 and 1,500 hours before failure (the Mean Time Between Failure, or MTBF), and reciprocating expansion engines could run for 800 hours for gas and 1,100 hours for liquids between failures. ${ }^{2-13}$ One interesting note was that the Fermilab staff discovered that magnet cooldown was very difficult due to system instabilities (flow reversals, or geysering) unless there was at least $20 \%$ excess refrigeration capacity present. Typical repair or replacement downtimes for these equipment items were: cold box, 146 hours; transfer line, 1 hour; compressor, 60 hours; wet expander, 1 hour; dry expander, 8 hours; and plugging leaky expander heat exchanger u-tubes took 0.1 hour per tube. ${ }^{2-14}$

Later work published on accelerator cryogenic cooling systems ${ }^{2-6}$ declared that a major problem of cryogenic systems was their reliability. The present helium refrigerators were cited as suffering from low reliability, premature component failures due to poor design, and operations related problems, such as contamination. Brown stated that only attention to reliability in all stages of cryogenic system design, fabrication, installation, operations, and maintenance - with a little good luck - would provide the satisfactory performance sought for Fermilab. 2-6 Indeed, discussions of accelerator major problem areas 
at that time showed that cryogenics is an area that requires redundant components and double the amount of calculated cooling ability. 2-15

Fermilab reported on their satellite liquid helium system, the forty-eight 251 iter/hour units, again in the early 1980's. This operations paper ratier fatalistically suggested that "redundant components significantly improved the likelihood of continued operation in the event of equipment failure"..$^{2-16}$ The initial subsystem interactions tests in June 1982 proved unsuccessful when the helium transfer lines and the magnets would not stabilize at operating temperatures, similar to the T-15 experiences. After two weeks, the testing was suspended. A 'brute force' approach of using all available LHe finally overcame the problem and allowed proper magnet cooling. The satellite expanders suffered several major mechanical problems, such as broken drive shafts and bad piston seals. An interesting problem with the magnet relief valves was that during magnet quenches, debris would be blown from the magnet interior into the relief valves, eventually clogging them. This and other problems, such as defective seals and weak welds, gave relief valve failure rates of 1 failure per 100 valve openings on magnet quench. ${ }^{2-16}$

More recent work published on the Fermilab TEVATRON accelerator main cryogenics system was more optimistic. The Fermilab central helium liquefier is rated at 5,000 liters/hour, using three large $1.5 \mathrm{MW}$ reciprocating helium compressors to give $4.5 \mathrm{~K}$ helium refrigeration. During the six year system preoperational testing and system debugging session, there were several major problems. In order of severity, these problems were: Expander low efficiency due to valve leaks, seal leaks, broken drive shafts, bad piston shaft seals, and large pressure drops when operating above $66 \%$ of rated speed; Contamination problems from water, nitrogen, and particulates; Control faults such as microprocessor rebooting, and communications link failures when building air temperatures rose above $32 \mathrm{C}$ or fell below $13 \mathrm{C}$; and Expander load regulation problems, such as blown fuses and expander runaways that forced emergency braking. The eighteen month system commissioning session also exhibited operational problems. These were: Contamination by nitrogen leaks through closed valves, and mixtures of aluminum oxides with water and nitrogen causing 
plugs in lines and in the turbine inlet filters; Control instability caused by heat loads that led to flow oscillations; Inadequate power lead cooling; Magnet quench relief valve leakage due to broken valve bellows and magnet clamp parts becoming lodged in the valve poppets; Magnet vacuum leaks; and Sixteen small pump motor failures. 2-17

Overa11, TEVATRON operations experiences showed that contaminants such as water (impurities as low as 0.7 parts per million, or ppm, by volume) and nitrogen (impurities as low as $1 \mathrm{ppm}$ ) can be a problem, even for 5,000 liter/hour systems. Pipe plugging by frozen carbon dioxide, and neon or hydrogen, occurred at least 8 times in the $5 \mathrm{~K}$ and $10 \mathrm{~K}$ helium piping, at one hour of downtime per event. Control system problems caused 10 to 15 hours of downtime per month, and human operations errors caused 2 to 3 hours of downtime each month. The liquid expanders, with the use of high performance Nitrile piston 0-rings and felt seals, have managed up to 3,000 hours of operations with no failures or major maintenance downtimes. Efficiencies up to $77 \%$ have been obtained for the expanders. This is the best performance obtained for these units over roughly nine years of testing and operations. ${ }^{2-17}$

\subsubsection{Intersecting Storage Rings Experiences. Surprisingly, the Center} for European Nuclear Research (CERN) reported that their cryogenics and refrigeration system for the Intersecting Storage Rings (ISRs) experiment performed flawlessly for the first 10,000 hours of operation. This operation included 15 cooldown/warmup cycles. The paper did refer to several component failures during commissioning, but gave no details about the failures. ${ }^{2-18}$ A paper on helium leak detection referred to an initial, persistent helium leak in the horizontal vessel of the cryostat that housed a CERN ISR magnet. The leak was large enough to hamper proper operation of the cryostat. A method was devised to locate the leak, so that complete cryostat disassembly and replacement would be avoided saving weeks of ISR downtime. ${ }^{2-19}$

\subsubsection{MSU Cyclotron Experiences. The superconducting cyclotron at} Michigan State University (MSU) suffered a leak of helium from the coil cryostat to the vacuum jacket. The leak was very small at room temperature, but rose significantly when the cryostat was cooled to 
cryogenic temperatures. When the diffusion pump on the vacuum jacket was turned off, the pressure in the jacket would rise by a factor of greater than 2 within 3 hours. ${ }^{2-20}$ These leaks are referred to as 'cold leaks', that is, a system appears to be vacuum tight at room temperature but leaks profusely when cooled to LHe or LN2 temperatures. ${ }^{2-21}$ The MSU cyclotron leak was a tolerated operational problem for over three years of cryostat operations. Finally, a new method to detect the leak, which turned out to be several leaks, was developed and tested by MSU researchers. ${ }^{2-20,2-22}$ Flowing cold gas over the exit ports of the cryostat provided the means to determine the leak locations in the upper part of the cryostat. Leaks in the lower part of the cryostat were roughly determined by tracking the cryostat's liquid helium level and the helium content in the vacuum jacket. The leaks have been sealed well enough now that the diffusion vacuum pump does not need to run continuously to maintain the vacuum pressure in the insulating vacuum jacket. Although helium cold leaks are said to be a common problem, MSU appears to have solved it for their cyclotron. ${ }^{2 \cdot 23}$

\subsection{Superconducting Magnet. Energy Storage Cryogenic System Operations}

There is only limited Titerature on Superconducting Magnet Energy Storage (SMES) system performance. The experience from one 30 MJ SMES unit was interesting for this report. A trailer mounted helium refrigerator, using liquid nitrogen for heat exchange and refrigeration shield, supplied a SMES unit for the Bonneville Power Administration (BPA) electrical grid. ${ }^{2-24}$ This refrigerator was a continual source of hardware and operational problems over the 1,200 hours of operation reported. The refrigerator responded very slowly to manual adjustments, with up to 12 hours of time lag. This was partly a funding limitation, which forced the BPA to purchase a unit that was not fully automated. Power outages to the refrigerator caused tedious and complex system recoveries. There were several unspecified mechanical component failures, usually repaired within hours by company personnel. Two design defects were discovered that forced the utility to de-rate the capability of the refrigerator by $30 \%$, and to revise the heat inleakage to a higher value. These two major design problems meant that the sustainable SMES unit power was decreased from $7 \mathrm{MW}$ to $4 \mathrm{MW} .^{?-? 4}$ 


\subsection{Medical Technology Magnet Cooling System Operations}

I have had a search of medical magnet experiences from the US Food and Drug Administration's event data base, called the Device Experience Network, ${ }^{2-25}$ performed under the US Freedom of Information Act. The time period I searched was 1980 to 1991. The results for cryogenic helium concerns with magnetic resonance imaging (MRI) units are given in Table 2-1. These cryogenic events and violations of regulations involve magnet quenches and violations of safety protocols. During magnet quenches, magnet heat boils some of the liquid helium coolant, so that gaseous helium has to be vented from the magnet case. The MRI magnet vent stacks to the atmosphere were breached or otherwise disconnected and allowed the helium gas to escape into the MRI patient scan room. The most extreme event of that type caused the MRI technician to break a window to enter the scan room so that he could rescue the patient, since the helium overpressure kept the technician from opening the door to the room. Some other events cited inspection results of oxygen monitors being either improperly mounted or not powered from battery-backed power sources, both of which are violations of safety protocol and the MRI unit manufacturer's suggested operating practices.

In closing, Table 2-2 summarizes information given in this chapter by citing brief phrase descriptions of the problem areas that have been discussed in this chapter. Some problems only hamper good operations, such as system pressure changes that reduce thermal efficiency. other problems can be safety or availability concerns, or even lead to cryogenic system initiating events (IEs), such as line plugging, valve leakage, leakage into the vacuum insulation space, etc., if they are severe enough. Component failure rates and cryogenic initiating event frequencies will be treated in following chapters. 
Event Date

November 11, 1988 During a magnet quench, the helium venting system failed and hellum began veriting into the scan room. The operator hurt his back while evacuating the patient.

January 1, 1989

During a magnet quench, the venting system failed, causing helium to fill the scan room. The patient bumped his knee while quickly evacuating the scan room. The vent pipe had separated from the magnet. body, causing a helium cloud to fill the room.

February 24, 1989 During a magnet quench, the he? ium vent system failed and vented tho gas into the scan room. The room pressure quickly increased, causing the scan room door to stick closed. The operator broke out a window between the scan room and control room to gain access to the scan room for patient evacuation.

Apri1 27, 1990

February 12, 1991

March 6, 1991 An oxygen sensor for room atmosphere to protect the patient in case of cryogen release was not mounted correctly and could not read the oxygen level in the MRI room.

A defective Balzer cold head (L.N2. thimble to cool the insulation space) was making enough training noises to hamper communications with the scan patient.

The magnet quenched, releasing helium into the magnet room. The venting system was repaired the same day. No one was present during the event. 
Event Date

May 2.4, 1991
Description of the Event

The scan room's oxygen monitor was determined to not have a battery backup. This is specifled in safety information, since the oxygen monitor must be operable at all times in case of cryogen release. The monitor w111 have a backup power source installed. 
TABLE 2-2. SUMMARY OF OPERATIONS PROBLEMS ENCOUNTERED IN LIQUID HELIUM AND LIQUID NITROGEN SYSTEMS

\section{Design-related Problems}

Improper size of system to deal with all scheduled modes of operation Inability of system to deliver rated temperature or flow rate Inability to cool down magnets to desired temperature Control system faults that led to system run on and premature shutdown Room oxygen monitors not functioning properly due to improper mount design System flow reversals, causing pressure oscillations and instability Slow system response to changed input parameters

\section{operations-related Problems}

Leakage of nitroger, helium, or atr into vacuum insulation jacket, or into the process piping

Leakage of water into system from the compressor or its heat exchangers Atmospheric humidity condensing onto exterior of cold piping Pipe and filter clogging due to foreign materials or frozen gases Spurious gas compressor shutdowns

System contamination from compressor oil, or construction debris Instrument failures, such as temperature and liquid level sensors Centrifugal pump seal failures, expansion engine piston seal failures Relief valves clogging from debris, or leaking past the seat Human operations errors Helium leakage out of small 'cold leaks' 
2-1. "The IEA Large Coll Task," Fuston Engineering and Design, I, September 1988, pages 56-89.

2-2. W. A. Fietz et a1., "Experience with Operation of a Large Magnet System in the International Fusion Superconducting Magnet Test Facility," Fuston Technology, 8, July 1985, pages 817-822.

2-3. P. N. Haubenrich et al., "Experience with Cooldown of Superconducting Magnet Coils in the Large Coil Task, "Fusion Technology 1986, Proceedings of the Fourteenth Symposium on Fusion Technology, Avignon, France, September 8-12, 1986, pages 1803-1809.

2-4. D. Ivanov and B. Stavisskij, "Experience of T-7 Operation in Plasma Experiments," Fuston Technology 1982. Proceedings of the Twelfth Symposium on Fusion Technology, September 13-17, 1982, pages $1087-1093$.

2-5. C. G. Pantano, Jr., and D. B. Dove, "Unusual failure mode of a liquid nitrogen feedthrough," Journal of Vacuum Science and Technology, 12, November/December 1975, pages 1427-1428.

2-6. D. P. Brown, "Cryogenic Systems for Large Superconducting Accelerators/Storage Rings," IEEE Transactions on Nuclear Science, NS-28, June 1981, pages 3214-3216.

2-7. N. N. Britousov et al., "Fusion Facility T-15: First Experiments with Electromagnetic System, "Fusion Technology 1990, Proceedings of the 16th Symposium on Fusion Technology, London, UK, September 3-7, 1990, pages 597-601.

2-8. B. Turck, "Tore Supra: A Tokamak with Superconducting Toroidal Field Coils, Status Report After the First Plasmas, "IEEE Iransactions on Magnetics, 25, March 1989, pages 1473-1480.

2-9. B. Gravil et a1., "Two Years of Operation of the Tore Supra Cryogenic System," Fusion Technology 1990, Proceedings of the 16 th Symposium on Fuston Technology, London, UK, September 3-7, 1990, pages 1649-1653.

2-10. G. D. Martin and C. V. Pak, "Operating Experiences of the 1070 Watt Liquid Helium TFTR Refrigerator System," Proceedings of the 12 th Symposium on Fusion Engineering, Monterey, California, October 12-16, 1987, pages 464-467.

2-11. W. Halchin et a1., "Operation of the ORMAK Device in a Cryogenic, Vacuum Environment," Proceedings of the Fifth Symposium on Engineering Problems of Fusion Research, Princeton University, November 5-9, 1973, IEEE Pub. No. 73CH0843-3-NPS, pages 360-363. 
2-12. H. M. Long and J. N. Luton, Jr., "Cryogenic Engineering for ORMAK," Proceedings of the Fifth Symposium on Engineering

Problems of Fusion Research, Princetori University, November $5-9$. 1973, IEEE Pub. No. 73CH0843-3-NPS, pages 380-384.

2-13. R. A. Andrews et al., "Hel lum Refrigeration System and Cryogenic System for Superconducting Switchyard Magnets at Fermilab," IEEE Transactions on Nuclear Science, NS-26, June 1979, pages 4093-4095.

2-14. P. D. Brindza et a1., "Energy Doubler Refrigeration System, "IEEE Iransactions on Nuclear Science, NS-26, June 1979, pg. 4102-4104.

2-15. A. V. Tollestrup, "Progress in Superconducting Magnet Technology for Accelerators/Storage Rings." IEEE Transactions on Nuclear Science, NS-28, June 1981, pages 3198-3199.

2-16. C. H. Rode et a1., "Operation of the TEVATRON Satellite Refrigerators for 0.75 - and 2.0-Kilometer Magnet Strings, "IEEE Iransactions on Nuclear Science, NS-30. August 1983, pg 2892-94.

2-17. C. H. Rode et al., "Operation of Large Cryogenic Systems, "IEEE Transactions on Nuclear Science, NS-32, October 1985, pages $3557-3561$.

2-18. J. Billan et al., "Operational Experience with the Superconducting High-Luminosity Insertion in the CERN Intersecting Storage Rings (ISR), "IEEE Transactions on Nuclear Science, NS -30, August 1983, pages 2036-2038.

2-19. Ph. Lebrun and $P$. Rohmig, "Localization of small leaks on the helium vessel of a cryostat," Cryogenics, 20. August 1980, pages $482-483$.

2-20. M. L. Mallory et al., "Operating Experience with the Cryogenic: Systems for a Superconducting Cyclotron," IFEE Transactions on Nuclear Science, NS-28, June 1981, pages 3263-3265.

2-21. T. H. Batzer and W. R. Call, "Liquid to Gas Leak Ratios with Liquid Nitrogen and Liquid Helium," Fusion Technology, 8 , July 1985, pages 1281-1283.

2-22. S. Sinharoy and W. J. Lange, "Behavior of small leaks in the presence of liquid or gaseous helium at $4.2 \mathrm{~K}$," Journal of Vacuum Science and Technology, 20. April 1982, pages 978.981.

2-23. M. L. Mallory, "Initial operation of the MSU Superconducting Cyclotron," IEEE Transactions on Nuclear Science, NS-30, August 1983, pages 2061-2064.

2-24. J. D. Rogers et al., "Operation of the $30 \mathrm{MJ}$ Superconducting Magnetic Energy Storage System in the Bonneville Pcwer Administration Electrical Grid, "IEEE Transactions on Magnetics, MAG-21, March 1985, pages $752-755$.

2-25. 21CFR803. Title 21 of the Code of Federal Regulations, Food and Drug, Part 803, "Medical Device Reporting", April 1, 1991. 


\section{Summary of Accidents in Cryogenic System Operations}

This chapter gives detalls of published accident information on cryogenic liquid and gas accidents. Cryogens other than nitrogen (LN2) or helium (LHe) are included here, since events with these other cryogens, such as liquid oxygen ( $L O X)$, hydrogen, ammonta, propane, liquefied natural gas (LNG), and liquefled petroleum gas (LPG), can be applicable to LN2 or LHe. Since LHe and LN2 are not explosive, any concerns of that nature for the other cryogens have not been treated. This chapter is by no means a complete review of all cryogenic accidents, but it is representative of the types of accidents that have occurred and could possibly occur again without proper design and operations precautions. Insights gained here al so support completeness in qualitative safety assessments. The chapter is structured to first discuss accident and incidents with US government funded scientific research projects, such as the space program. Then chemical industry events are discussed, followed by ozone explosions. Fires near cryogenic systems, and large releases from cryogenic storage tanks are discussed. Lastly, I close with discussions of human errors in fusion cryogenic systems and events that have occurred with small cryogenic dewar containers.

\subsection{Chapter Summary}

This chapter cites incidents of large cryogenic gas releases to buildings or the atmosphere because of equipment material fallures, operator errors, weld failures, and contaminants in the cryogen that caused phase changes. Judging from the chemical industry events, the public can be endangered, and there is a very negative public opinion associated with these releases. I extrapolate that large "white cloud" releases would create a media sensation at a future fusion facility. Workers are also at risk when dealing with cryogenic systems. A large nitrogen gas release in the Netherlands in 1972 caused several fatalities. Also, in 1953, a nitrogen gas release event in a Japanese air separation plant nearly suffocated 5 workers.

There have been several ozone explosion events in irradiated LN2 systems, as early as the 1950's and as recently as the $1970^{\prime} \mathrm{s}$, with two 
probable events in the 1980's. Damage from ozone-rolated events has ranged from minor effects to equipment so badly damaged that replacenint was the only means of repalr.

\subsection{Cryogentc Accidents in US Government operations}

National Aeronatics and Space Admintstration (NASA) hydrogen release events were collected and reviewed for safety insights in posslbly using 1 lquid hydrogen for automobtle fuel. There have been 96 hydrogen mishaps, most being liquid hydrogen releases, reported in the records kept by NASA for the time period between NASA inception in 1958 and $19733^{31}$

These events are too numerous to reproduce here, and since the original report is quite cryptic in accident descriptions a reproduction of the events would not be meaningful. Most of the events were large enough releases to pose a safety threat. The summary information about these events is valuable and is given below. The following is an approximate breakdown of the causes of the 96 hydrogen m/shaps reported:

$\begin{array}{lc}\text { Valve malfunctions or valve leaks } & 20 \% \\ \text { leaking connections or fittings } & 16 \% \\ \text { Safety rupture disk fallures } & 11 \% \\ \text { Materials failures (hydrogen embrittiement, etc.) } & 11 \% \\ \text { High venting rates (system design inadequacies) } & 11 \% \\ \text { Cryopumping (discovery of 'cold leaks') } & 10 \% \\ \text { Air trapped in systems (flanmable mixtures formed) } & 5 \% \\ \text { Highway tanker truck accidents } & 5 \% \\ \text { System overpressure, bellows ruptures } & 4 \% \\ \text { Hydrogen evolution from batteries } & 4 \% \\ \text { Tank and ine ruptures, insulating vacuum 10sses } & 3 \%\end{array}$

In $69 \%$ of the incidents, hydrogen was released to the atmosphere. This percentage includes the 5 tanker truck accident events. Most of the rest of the report dwells on ignition of the hydrogen gas, whtch is a primary safety concern for that lighter than atr, flammable gas.

INASA oxygen release events were also reviewed. $3 \cdot ?$ There were 55 events involving liquid oxygen (L.Ox) between 1958 and 1970 in NASA 
operations. These 55 L.0x events are summartzed by major cause:

$\begin{array}{lc}\text { Matertals fallures/incompatibllities } & 29 \% \\ \text { System contamination } & 20 \% \\ \text { Other (personnel errors, etc.) } & 18 \% \\ \text { Ignttion source near vent outlet } & 11 \% \\ \text { Tank, litne ruptures } & 9 \% \\ \text { Valve malfunctions and errors } & 7 \% \\ \text { Lox delfvery accidents and releases } & 6 \%\end{array}$

When oxygen was released, tt went directly to the atmosphere because of the general nature of engine test stands. About $56 \%$ of these 55 LOX events resulted in explosions or fires. Intrusion of forelgn matertals, suci as hydrocarbons, alumtnum metal shavings, steel fines from surface abraston (pump impeller shaft and valve seat wear), materials left in the system (most notably cleaning flutd jugs and pads), cleaning fluid corrosion products on the ptpe walls, etc, caused the system incompatiblitties and contamination events. Poor welds and metal chamber wall fallures caused the rest of the materials fallures.

U.S. Department of Energy (DOE) operational occurrence reports were searched for cryogenic events, as well as pertinent journals. Table 3-1 gives past events from published reports ${ }^{3-3}$ and 11 stings from the Occurrence Reporting and Processing System (ORPS). ${ }^{3-4}$ The breakdown of events from Table 3-1 is: Gas compressor explosions and fires, 4 events; Cryogentc overpressure explostons, 2 events; Loss of insulating vacuum, 2 events; Accelerator window fallures, 1 event; Hydrogen explosion, 1 event; Bellows liner fallure, 1 event; and Helfum refrigerator shaft fatlure, 1 event. In another DOE event, the Alcator $C$ fuston facility had an air leak into a magnet cryogentc enclosure. Ice butlt up overnight, blocking flow. The coll was damaged beyond repatr when it was operated the next operating day. ${ }^{3-5}$ 
TABLE 3-1, CRYOGENIC EVENTS FROM U. S. DEPARTMLII OF ENERGY OPERATIONS

Event Dale

June 28,1960

Ju1y 21, 1964

November 16, 1964

July 5,1965

March 18, 1966
Description of Event and Reference Number

The stainless steel lining of a new liquid nitrogon storage lank being installed collapsed when its contents were partly evacuated during an acceptance test. The event cost was $\$ 7,000$ to repatr the tank. Report $60-21,3 \cdot 3$

An explosion look place in a hydrogen purifier for a bubble chamber expansion system when a valve was inadvertently left in a closed position during purging operations. The precooler and the adsorber cotls were torn open and the containtry dewar bulged. The event cost \$11,000 for repatrs. Report $64 \cdots 41 \mathrm{~B}, 33$

An explosion accurred in the first stage of a nitrogen compressor, resulting in shrapnel being thrown through the compressor bullding roof and also dallaying the building walls. Repairs cost $\$ 16,000$. Report 64-59B.3.3

An explosion and fire occurred in the experimental hall of an accelerator complex. The incident was calused by a sequential failure of the inner and outer beryllium windows of a liguid hydrogen bubble chamber. One person died and seven others were injured. The repair cost was $\$ 1.5$ million. Report $65-24.9 .3$

When the main hydrogen flow through a purifier was begun, an explosion occurred at the inlet to the adsorber coil. Immediately, the liquid hydrogen contents of the chamber were dumped to the atmosphere through a safety vent system. Repairs cost $\$ 11,000$. Report $66 \cdot 8,3 \cdot 3$ 
TABLE 3-1. CRYOGENIC EVENTS FROM U. S. DEPARTMENT OF ENERGY OPERATIONS (Continued)

Event Date

June 27,1966

December 24, 1967

January 13,1982
Description of Event and Reference Number

An explosion (the cause was undetermined) occurred in a nitrogen compressor, followed by a lower intensity explosion in an oll demister downstream from the compressor. Two men, located 2 and 4 meters from the point of major fallure of the compressor, were not injured. Repairs cost $\$ 40,000$. Report $66-26,{ }^{3-3}$

A fire, probably originating in electrical wiring, occurred in the compressor tratler of a bubble chamber facility. The compressors and associated piping, and wiring were damaged. Repairs cost $\$ 15,000$. Report 67-50.3-3

During liquid helium transfer to cryopanels, a valve leading to the magnet dewar spuriously opened and allowed the helium to flow into the warm dewar. The liquid helium bolled and the resulting overpressure caused a helium gas recovery bag to rupture. An overpressure relief type of device will be added to the gas recovery system. ${ }^{3-6}$.

1986
The Fermilab nitrogen reliquefier suffered a major delay when a $254 \mathrm{~mm}$ diameter pipe bellows 1 iner failed. The reciprocating compressor was damaged, and rework and recommissioning added to the delay. The liner was excited by an upstream compressor bypass into a resonant failure. The bypass line was moved to another position in the system. ${ }^{3-7}$ 
TABLE 3-1. CRYOGENIC EVENTS FROM U. S. DEPARTMENT OF ENERGY OPERATIONS (Continued)

Event Date

June, 1987

March 23, 1990
Description of Event and Reference Number

The Tritium Systems Test Assembly suffered a helium refrigerator failure in their hydrogen isotope separation system. The shaft that coupled the expansion engines to the inlet and outlet valves broke during operation. The major test run in progress had to be postponed while repairs were made. The test run was subsequently performed in JuTy $19877^{3 \cdot 8}$

The liquid helium compressor for a superconducting magnet was in operation when there was a site-wide power surge. The compressor contactor failed to break power to the compressor motor during the power dip, which caused the $300 \mathrm{~kW}$ motor to short circuit and fail. A technician quickly shut down the system in an orderly manner and discharged a portable fire extinguisher, because smoke was present around the motor. Undervoltage and underfrequency protective relays will be installed. Repairs cost an estimated $\$ 6,000 \cdot 3-9$

July 19,1991
An unplanned superconducting magnet discharge was initiated when an isolation amplifier input cable was disconnected inadvertently. Some minor damage occurred to insulation on a current lead-in during an arc to ground. A $G-10$ insulator disc melted in the arc that passed through a $1 . \mathrm{cm}$ distance at the current lead joint. The arc opened a hole in the stainless steel jacket, allowing liquid helium into the vacuum space of the tank. Helium was 
TABLE 3-1. CRYOGENIC EVENTS FROM U. S. DEPARTMENT OF ENERGY OPERATIONS (Continued)

Event Date

July 19, 1991 (con't.) vented into the laboratory and to atmosphere via pressure relief valves. Water coolant from the damaged current lead entered the magnet, requiring warm up and drying before resuming operations. The magnet coil itself was not damaged. More distance will be provided at the current lead joints. Repairs will be completed by September 24, 1991 and cooldown should begin on October 1 , 1991 . $^{3-10,3-11}$. 


\subsection{Cryogenic Accidents in the Chemical Industry}

The liquefied natural gas (ING) and liquefied petroleum gas (LPC) industries have had many serious accident events. LNG and LPG events are discussed first, then other liquefied gas accidents are treated. These events serve to illustrate several points u" good design. Proper materials must be used, systems must be inspected regularly for leaks, and proper procedures for system operations must be followed. A good summary of chemical industry accidents is given by lees. ${ }^{3-1}$ ? Several accidents of potential concern to fusion are a 1961 compressor explosion in an oxygen plant in Ecorse, Michigan, a 1964 oxygen plant explosion in Charleston, West Virginia, and a 1972. nitrogen release event in Rozenburg, the Netherlands that asphyxiated three people. These explosions resulted from large breach events mainly due to material failures. other events are the Cleveland, Ohio LNG storage lank leak and explosion in 1944 (the tank materials were not suitable for ING temperatures, became brittie and failed) that killed 144 people. In November 1970, operators at Gulf 0il's Blair, Nebraska plant accidently overfilled a refrigerated ammonia storage tank. The tank released about 145 metric tons of ammonia, but no one was injured. An LPG rail car derailment in Crescent city, Illinois, in June 1970, caused a large LPG explosion. Heat from the ensuing fires caused other, intact tank cars to overpressurize, and open their pressure relief valves, feeding the fire with more petroleum gas. A major leak of ammonia from a pipeline in McPherson, Kansas in December 1973 occurred due to a block valve failing to open in the pipeline. The pipeline overpressurized and ruptured. No one was injured. A summary of the 295 public evacuation events from the vicinity of chemical plants in the US between 1980 and 1984 shows the frequency of chemical plant events and the increasing public hostility toward that industry. 313 Several of those evacuation events dealt with releases of $I N G$, I.PG, anmonia, and chlorine. Carson ${ }^{3-14}$ also gives tables of many chemical industry events, including ammonia, propane, I.NG, and I.PG accidents.

Since many of these release events happened because of material failures, proper materials are very important to cryogenic systems. Materials considerations are also important. in fission reactor systems, to avoid embrittlement. Materials considerations will be taken into account 
when I set the order-of-magnitude failure rates for cryogenic components, such as piping, valves, cryostats, cryogenic storage tanks, etc., in Chapter 5.

Air separation plants have had their share of unfortunate events as we11. While most are explosions of liquid oxygen, there was one event at a Japanese facility in 1953. Two workers went into a heat exchanger pit to plug a leaking heat exchanger tube. While working in the heat exchanger, nitrogen gas overcame them. Three more workers saw these two men in danger, and they rushed in to the pit to rescue them. All five were overcome and nearly suffocated before the nitrogen flow was stopped and rescuers with portable breathing apparatus rescued the five..$^{3-15}$

Some recent accidents in Europe also show some of the risks in working with cryogens. In 1983, a pipe fitter at an ammonia plant was changing the valve operator from a manual handwheel to a motor operator. The fitter inadvertently began working on the wrong valve, and removed all four bolts that held the valve cap in place (rather than one at a time, as the procedure directed). The fitter was choked by anhydrous ammonia when line pressure blew the valve cap off. ${ }^{3-16}$ In another event, a compressor house in an ammonia plant had a fire in 1983. A lubricating oil line for the ammonia compressors suffered a breach failure from vibration. The oil caught fire in the warm plant environment. A plant operator walking through the plant noticed the flames and sounded the fire alarm. Several plant operators battled the fire, using more than ten portable fire extinguishers. The fire kept reigniting, since oil was still being supplied and the portable extinguishers were not large enough to cool the environment adequately. One operator suffered a fatal heart attack from the stress and physical exertion of fighting the fire. When the compressor and the lube oil pump were shut down, a standby electrical lube oil pump started (designed to protect the compressor in case of low oil levels) and also had to be shut down, since it added more oil to the fire. Firemen arrived and finally extinguished the fire by cooling down the surrounding area. Damage to the plant was over $\$ 0.6 \mathrm{M}$, and the plant was down for about two weeks for repairs. ${ }^{3.17}$ This compressor fire event is particularly important to us, since small compressor and turboexpander oil leaks have been noted as operational problems in Chapter 2. 
Accidents with liquefied propane gas have also occurred. A propane truck, overfilled and with the safety reliof valves inoperative, exploded outside the driver's home. The driver had goule to lunch, leaving lhe truck motor idling. The heat from the exhaust pipe warmed the stationary vehicle's propane tank. These three conditions combined (overfill, heating, and fallure of pressure relief) caused a propane warmup, pressurization, and explosion. The truck was destroyed. ${ }^{3-18}$ In Japan, some year-old liquid propane cylinders split open and discharged their contents. There were no reported effects from the propine release. Metal fault inclusions in the drawing processes for the cylinder end caps were found to be the cause of the cylinder fractures. 3-19 Lees ${ }^{3-12}$ also mentions delivery truck accidenls leading to releases and explostons, notably the 1978 disaster in spain where a propane tank truck exploded, the 1976 accident, with an ammonia tank truck in Houston, Texas, and the 1970 lox tank truck explosion in Brooklyn, New York. Release events from delivery trucks could also happen with IN2 or LHe.

The use of perlite insulation for ING and IPG has also led to several failure events."? When the perlite in the vacuum insulation space settles and packs down, the local heat transfer rate increases, which has led to overpressure accidents. Equipment under vibration, such as truck or rail transport, has the highest risk of this type of event. However, perlite can also be beneficial. For large storage tanks, perlite has been shown to have a significant damping effect if the inner tank wall fails, restricting the size of the inner wall brak and retalding the cryogen outflow. ${ }^{3 \cdot 21}$ Fortunately, liquid hel ium fusion uses recuiring absolute minimization of heat transfor would likely require the more advanced aluminized mylar sheot insulation rather than perlite.

\subsection{Ozone Explosion Events}

Another major safety concern for reryogenic systems is creation of ozone in systems that entrain oxygen and are under irradiation. There have been several events of ozone explosions in the 1950's and 1960's, and there are two additional possible nzone events in the U.S. DOF ORPS data base in the $1980^{\prime} \mathrm{s}$. These ozone events are cited in Table 3-?. Oxygen impurities in commercial liquid nitrogen or in nitrogen systems 
Inadvertently exposed to air can begin to form ozone in the presence of radiation, such as gamma rays or electron beams, or by neutron bombardment. Brereton ${ }^{3-2.2}$ calculated that for $10 \mathrm{~m}^{3}$ of $\mathrm{LN2}$, with an initial oxygen impurity concentration of $20 \mathrm{ppm}$ (to accourit for air inleakage) and a gamma/neutron exposure for a $500 \mathrm{MW}$ Burning Plasma Experiment (BPX) pulse, the ozone creation is on the order of 75 grams. For that amount of ozone, the decomposition energy is roughiy $226 \mathrm{~kJ}$, or about the same as detonating a quarter of a stick of trinitrotoluene (TNT, about $50 \mathrm{~g}$ per stick). If the ozone was allowed to build up for all of the 3,000 BPX full power pulses, the decomposition energy could have been as high as $678 \mathrm{MJ}$ (or about 680 sticks of TNT, since TNT is roughly $1 \mathrm{MJ}$ per stick).

For systems that are meant to remain cold after initial startup, such as refrigerating shields and cryotraps, the buildup of ozone could be a problem. The ozone freezes out on the LN2 pipe walls, so it can accumulate in the radiation field's location. Milligram quantities of ozone can be created from oxygen impurities in just minutes of medium to high irradiation. Since commercial liquid nitrogen is generally now much purer than that in the $1960^{\prime} \mathrm{s}$, the ozone formation concern is reduced, but air inleakage must be kept to a minimum to keep the oxygen concentration near the commercially obtainable 5 ppm. ${ }^{3-22}$

Ozone creation in LHe systems is also a safety concern for fusion. The oxygen impurity will freeze out in LHe, but small air leaks into the system near the tokamak neutron and gamma radiation field will still allow ozone creation. ${ }^{3-22}$ Another source of air admission is a vessel leak-up-to-air event, where the oxygen in air freezes out in liquid helium or liquid nitrogen cryopumps. Such an event was postulated during the TFTR safety work. ${ }^{3-23}$ A variety of ozone ignition sources could be present: vibrations from machine operations, static electricity buildup, impact from other foreign materials circulating in the cryogenic system, and cryogenic system pressure fluctuations or localized heating that could dislodge ozone chunks so that they would impact at a downstream bend in the piping. There are probably other ignition sources as well. 
TABLE 3-2. OZONE EXPLOSION EVENTS FROM LIQUID NITROGEN IRRADIATION

Event Date

$1955-1957$
Description of Event and Reference Number

Two explosions at the Oak Ridge Graphite Reactor. In the first explosion, an open mouthed aluminum dewar was filled with L.N2. The $6.5 \mathrm{~m}$ dewar, positioned inside the reactor, operated for 3 days before the explosion occurred. Afterward, there was an intense odor of nitrous oxide associated with ozone. ${ }^{3-24}$

The second explosion occurred during a cryostat run. A vacuum line to the LHe cryostat ruptured, allowing air to enter and freeze in the sample chamber. After the test run, when the cryostat was warming up, it exploded. ${ }^{3-? 4}$

Another explosion at the Oak Ridge Graphite Reactor. An open dewar of L.N2 was irradiated and it exploded. ${ }^{3-25}$

Harwell Laboratory researchers noted several explosions while conducting electron irradiation experiments with $1 \mathrm{~N}_{2}$ present. They attributed these to ozorie production and explosion. ${ }^{3-26}$

Hanford laboratory researchers noted several ozone explosions when they tested materials in electron beams generated by their Van de Graff accelerator. IN2 was used to cool the samples during the electron bombardment. ${ }^{3-28}$

During tests of the Nuclear Engine for Rocket Vehicular Applications (NERVA), liquid hydrogen lines caused air to freeze and pool near the surface of the cold gaseous hel ium shroud. Radiation from the NERVA test caused ozone formation and subsequent detonation. $3 \%$ 
TABLE 3-2. OZONE EXPLOSION EVENTS FROM LIQUID NITROGEN IRRADIATION (Continued)

Event Date

May, 1969

1969

June 5,1987
Description of Event and Reference Number

A LoS Alamos employee was testing superconducting colls for radiation resistance. An L.N2 dewar ran almost dry, and the employee removed it from the gamma radiation field to refill it. He carried it to the refilling station and set the dewar down on the floor. The mild jarring when he set the dewar down caused an explosion. The top of the dewar was blown off. The man was not hurt, other than a bloody nose and damage to his safety glasses. ${ }^{3-28}$

The cryostat at the Ames Laboratory Research Reactor operated successfully with high purity, oxygen free LN2 for many weeks. Then, when the cryostat was opened for a short time (about 45 minutes) to exchange irradiation samples, oxygen was admitted. After 2.5 hours, the cryostat began losing vacuum. The inner chamber had ruptured from an ozone or hydrocarbon explosion. 3-29

Continuous Air Monitors began sounding and an operator heard a sound like a large door slamming. Operators tried, but could not stabilize the cryogenic section of their radioactive rare gas treatment unit. An ozone or hydrocarbon explosion is believed to have occurred from oxygen inleakage to the liquid nitrogen cryogenic system. The cryogenic unit's vessel was ruptured by the explosion. A 3 month delay resulted when the vessel had to be replaced. corrective actions included changing the flow sheet and operations procedures to preciude future events. ${ }^{3-30}$ 
TABLE 3-2, OZONE EXPLOSION EVENTS FROM LIQUID NITROGEN IRRADIATION (Cont inued)

Event Date

May 2, 1989
Description of Event and Reference Number

A cryopump was being warmed to release frozen

gases trapped in the pump. An explosion occurred, which blew off the lower 203 mm diameter pump flange and crushed the lab jack below the flange. The pump walls were distorted and the inner cryoshields were mangled. The entire vacuum chamber was lifted from its supports and misaligned. Potential causes for the event were: an ozone explosion created from the operation of the sputter ion gun, or gases forming an explosive mixture (ignited by a thermocouple gauge).

Changes to preclude event recurrence included more frequent regeneration of the pumps to avoid ozone buildup, evacuating the cryopump with a roughing pump to reduce foreign materials buildup, and installation of an additional relief valve. ${ }^{3 \cdot 31}$ 


\subsection{Fires in Facilities that Use Cryogenic Fluids}

Fires near cryogenic equipment are a safety concern for the LNG community, ${ }^{3-32,3-33}$ and should be for all cryogenic gases. This is because of the extra heat load that fires can create near cryogenic storage tanks or plping. We have already read four nitrogen and hydrogell compressor explosion/fire occurrence summaries (gtven in Table 3-1). For fusion facilities, there are other chances for fires due to the high voltages, high frequenctes, and high electrical power levels required for plasma heating, magnet power, diagnostics, instruments and controls, and secondary system operations, such as water systems and cryogenic cooling units. Even though the fires discussed here are not near the cryogentc systerns, there is a chance that a fire could spread into other areas unless it is adequately blocked by ftre barriers. Since fuston facilities need so many services routed to and from the torus, the torus is a locus for possible fault events.

Reports of fires at fusion facilities are rare, but there are several events to mention here. One electricai fire event occurred at the Princeton Plasma Physics Laboratory. ${ }^{3-34}$ In September, 1970, two ground resistors on a $138 \mathrm{kV}$ to $4160 \mathrm{~V}$ transformer began smoking and then burst into flames. Timely operator intervention with portable fire extinguishers limited the spread of the fire so that only three $4-\mathrm{kV}$ circuit breakers were badly damaged and two others moderately damaged. The fire was extinguished before the local fire department arrived at the scene. The other event occurred at the DIII-D reactor near San Diego, California, in the 1980's. A forelgn object in the toroidal field coil electrical buswork on the floor below the torus caused a short circuit, then a minor explosion and fire. ${ }^{3-35}$ There has also been an electrical explosion event at the Joint European Torus in November 1983. A poloidal field coil power system circult breaker protection switch, operating at $2 \mathrm{kV}$ of its rated $24 \mathrm{kV}$, exploded for unknown reasons during the final run before a scheduled shutdown. The electrical protection system acted correctly to shut down the coil. A spare switch was installed during the ensuing maintenance shutdown, but the cause of the explosion was not identified. ${ }^{3-36}$ 
Another fire event of interest occurred during the construction of a liqutd ammonta storage tank in Canada in 1966. Durtng the construction process, a valve on the bottom of the tank had frozen shut, due lo could weather and condensation dratmage in the lank. A mochanic: Lrtod to heat. the valve with a propane torch to thaw it out. Unfortunalely, the urethane insulatton on the tank was seal coated with filtiticote (asphalt and gilsontte, blended with 100-flash potroleum solvent, asbostos flbers and mica filler). The seal coat caught fire from the torch's heat. The fire quickly spread to engulf the entre tank. The mechants barely managed to escape. Equipment thems noar the tank, such as woldors, atr compressors, kerosine heaters, etc., were destroyod. The fire burnod flercely for a few minutes and then died out. later, the contractor discovered that the petroleum solvent would be exuded from the seal coat. for up to 30 days, unt th the coat had cured properly. 3.37 fires, of industrial and electrical origin, should bo carefully analyzed for fusion facilities.

\subsection{Large Storage Tank Accidents}

Cryogente storage systems, generally large (hundreds of cubic meters capacity) insulated tanks, have been subject to accidents. Design precautions of dikes to prevent licuid flow away from the tank and cylindrical bund walls to confine liquid in a bolling pool around the tank appear to be generally effective for the LNG industry. Using crushed gravel as a flooring materlal near the tanks also helps the released liquid to diffuse and warm up. ${ }^{3} 38$ of course, these added expenses are assumed because of the large scale effects and loss of life that lNa explosions have been known to cause. The largost. NASA storage tank incident occurred in August 1966.3.34 A large lox tank was golng to be partially emptied as part of normal operations. When the out let valve was opened, 1.0x entered the outlet line, as normal. Then, the warm line caused heating and phase change in the flowing lox. Pressure pulsations occurred as the warm yas bullt up pressure in the outlet line. The resulting pressure pulsations, often referred to as 'water hammer', caused a 457 -min diameter metal flexible hose to twist and tear open. About $2,755 \mathrm{~m}^{3}$ of Lox was released. The cold flutd caused the transfer pump carbon steel base plate lo crack, and caused minor cracks in the 
storage vessel support columns. The Inner sphere of the storage tiank buckled trward due to the decreased pressure th the ullage space as the l.ox rapldiy dratned. The inner sphere was made of 304 stainless steel, and tt was later fllled wth water and pressurtzed to force the sphere back tnto shape. At $41.4 \mathrm{kPa}$ above atmosphertc pressure, the damaged area "popped out". The storage tank was ready to recetve Lox one month after the event occurred. Conference particlpants hearing this paper presentation suggested that preachlling the outlet line would prevent recurrence of the event. ${ }^{3-39}$ These pressure pulsations have been described as geysering. ${ }^{3-40}$ Ceysering is a phenomenon of gaseous and liquid cryogen coexisting in a vertical line. The dowriward flowing ilquid forces the vapor up, violently expelling the vapor into the chamber or contatner. The vapor causes a pressure increase whtch causes a pressure wave, or water hammer, that travels back down the vertical Iine, sometimes with disastrous consequences. The geysering inhtbitor 3-10 is an annular line, cooled to cryogentc temperatures, to prechill the transfer line and prevent large amounts of vapor formation.

Another tank fallure occurred for a liquid ammonta tank in November 1978. 3-11 This tank had two simultaneous problems. Cold weather and a power outage combined to fall the tank. When a plant-wide power outage occurred, the pressure transmltter for the tank froze up due to motsture in the instrument atr system and also the cold weather $(-12 \mathrm{C}$ ambient temperatures). When power was restored, the transmitter read a false low signal. The refrigerating compressors serving the lank actuated and began to run continuously, cooling the ammonta more than normal. Two days later, the incoming plant shift personmel noted the refrigerating compressors were st 111 running, and they realtzed that something was serlously wrong. Before they could act, the tank had collapsed inward. Operators shut down the compressors immediately, but the tank collapsed a second time, creating a small rupture in the tank. The tank had adequate overpressure rellef valves, but not vacuum relief valves. 2,267 metric tons of ammonta were lost due to the rupture and the repair operations. Tank insulation was removed, the damaged panels were cut out and replaced. Repair operations took almost 3.5 months. ${ }^{3-41}$ 
Storage tanks are susceptible to human errors and to the elements, such as the cold weather related fallure discussed above, and to other external events, such as earthquakes or aircraft crashes. In chapter 2, I noted several events of lank overfilling due to operator error, and there are more events Itke that in the 1tterature. ${ }^{3-42,43}$ I also note that oll storage tanks suffered damage in an earthquake event in October 1979. 311 Tank anchoring is recommended to prevent liftoff in the event of strong ground motion. Earthquake analysis for fusion factlities must be performed, espectally for the case of large IN2 releases. Japanese experfence with underground ING storage tanks has been favorable. Designed as tall cylinders to reduce sloshing flutd impacts to the tank celling in case of earthquakes, these tanks have performed well for many years, and are not visible to passersby. 3. ti

\subsection{Selected Human Error Events Involving Fusion Cryogenic Systems}

I have been told of two everits it fuston facility cryogentc systems that involved human errors. The first event happened in the 1970's. It was a flange breach, due to a cuality assurance error that allowed workers to inadvertently use carbon steel bolts in a cryogenic flange. ${ }^{3.46}$ The carbon steel bolts embritted at cryogenic temperatures and fractured. The second event, in the 1980's, was the inadvertent installation of a ball valve not intended for cryogenic service in the outlet line of a liquid nitrogen storage tank. When the ball valve was closed for the first time, a small amount of liquid was trapped in the ball's flow channel. Such a valve meant for cryogenic service has a small port arilled in the bal1, so that any fluid trapped there can exhaust downstream as it vaporizes. This inappropriate valve trapped LN2 in the flow channel. The valve suffered an overpressure within the ball charnel that forcefully tore open the valve body and allowed the tank contents to be vented to the atmosphere. ${ }^{311}$ No one was injured in either of these cases.

\subsection{Incidents with Small cryogenic Containers}

Other events in the literature are dewar overpressure explosions. These referenced cases describe dewar fallures from corrusion, air 
humidity icing inside the vacuum space that collapsed the dewar neck, and an tce plug from atmospheric humidity that formed in the neck of a dewar. Readers will recall that dewars are simply insulated containers that do not suppress cryogen bolling, but merely reduce heat inleakage to retard bolling. Normal heat inleakage boiloff was prevented by the ice plug, and the dewar pressure rose until the materlal falled in an explosive pressure release. ${ }^{3-48,3-49}$

\subsection{Conclustors}

A great deal of practical information on accidents has been obtained from cryogenic system operating experiences, most notably from the reported events in NASA, DOE, and chemical industry operations. The review of $L N G$ and other cool gas information has shown that attention to details, such as use of proper materials, adhering to system cleanliness requirements, and following good operating procedures helps insure safe operations. We have seen that cryogenic equipment (compressors and expanders) have matntenance and service life eccentricities, and can have dismal service records. Creation of ozone in LN2 can be suppressed by starting with very high purfty cryogens, and with cautious operating practices the ozone threat can be managed by eliminating iryogen exposure to atr. Table 3.3 gives a summary of the types of events discussed here. 


\section{Design related events}

High venting rates (system design inadequacies)

Discovery of 'cold leaks'

Air trapped in 1 iquid hydrogen systems, flammable mixtures iormed Helium refrigerator shaft failure from improper design

Ozone explosions in LN2 systems under irradiation

\section{Operations related events}

Cryogen rail tank car derailment and tank truck accidents Storage tank overfill spills

Human errors on cryogenic systems, supplying incorrect equipment

Fires potentially near cryogenic systems

1953 near-suffocation event

\section{Equipment related events}

Valve malfunctions and valve leaks

leaking connections or fittings

Safety rupture disk spurious failures

Materials failures (from hydrogen embritilement, etc.)

Tank and line ruptures

Loss of insulating vacuum

Accelerator window failures

Bellows liner failure

1972 nitrogen asphyxiation event

Pipeline ruptures

Liquid propane truck explosion, storage cylinder fracture

Titan missile fuel leakage due to materials problems, human errors

Large cryogenic storage tank failures

Dewar failures 
3-1. P. M. Ordin, Review of Hydrogen Accidents and Incidents in NASA Operations, National Aeronautics and Space Administration Technical Memorandum, NASA TM X-71565, 1974.

3-2. P. M. Ordin, Mishaps with Oxygen in NASA Operations, NASA Technical Memorandum, TM X-67953, 1971.

3-3. Operational Accidents and Radiation Exposure Experience Within the United States Atomic Energy Commission, 1943-1975, WASH-1192, Fal1 1975.

3-4. US Department of Energy, Order 5000.3A, Occurrence Reporting and Processing of Operations Information, revised on July 8, 1991.

3-5. D. B. Montgomery, "Review of Fusion Magnet System Problems," Proceedings of the IEEE Thirteenth Symposium on Fusion Engineering, Knoxville, TN, October 2-9, 1989, pages 27-31.

3-6. US DOE, Safety Performance Measurement System, organization code 8004003 , report number 82022 .

3-7. G. T. Mulholland et al., "Design and Operation of a 90,800 Kilogram per Day Nitrogen Reliquefier for the Fermilab Energy Saver, "Advances in Cryogenic Engineering, 31, 1986, pages $1087-1094$.

3-8. J. L. Anderson et al., "Experience of TSTA Milestone Runs with 100 Grams-Level of Tritium," Fusion Technology, 14, September 1988, pages 438-443.

3-9. US DOE, Safety Performance Measurement System, organization code 8003003 , report number 90008 .

3-10. US DOE, Safety Performance Measurement System, 10 day occurrence report, SAN--LLNL-LLNL - 1991-1026.

3-11. K. I. Thomassen, "Report on FENIX Incident," Presented to the 2nd Magnet Reliability Workshop, Boston, MA, August 14-15, 1991.

3-12. F. P. Lees, Loss Prevention in the Process Industries, Butterworths, London, 1980, Volume 2, Appendix 3, Case Histories.

3-13. J. H. Sorensen, "Evacuations due to off-Site Releases from Chemical Accidents: Experience from 1980 to 1984," Journal of Hazardous Materials, 14, 1987, pages 247-257.

3-14. P. A. Carson, "An Analysis of Incidents Involving Major Hazards in the Chemical Industry," Journal of Hazardous Materials, $\underline{3}$, 1979, pages 149-165. 
3-15. Survey of Accidents at the Air Separation Plants, NASA TT F-13388, National Aeronautics and Space Administration (translated from Japanese), December 1970.

3-16. F. G. Friedrichsen, "An Ammonia Accident in Denmark," Plant/Operations Progress, 2, April 1983, pages 122-123.

3-17. A. Mullier et a1., "Fire in a Compressor House," Plant/Operations Progress, 3 , January 1984 , pages $46-49$.

3-18. H. S. Pearson and R. G. Dooman, "Fracture Analys is of Propane Tank Explosion," Case Histories Involving Fatique and Fracture Mechanics, ASTM STP-918, American Society for Testing and Materials, 1986, pages 65-77.

3-19. K. Mogami et al., "Failure Analysis of a Liquid Propane Gas Cylinder," in Analyzing Failures: The Problems and the Solutions, American Society for Metals, 1985, pages 75-80.

3-20. H. M. Long, The Industrial Application of Vacuum Insulations," Vacuum Technology at Low Temperatures, AIChE Symposium Series 125 , Volume 68,1972 , pages 50-54.

3-21. A. S. Adorjan et al, "Double-Walled Cryogenic Storage Tanks Effect of Perlite/Fiberglass Insulation on Dynamic Loads in Case of Inner Tank Failure," Cryogenic Processes and Equipment 1982, AIChE Symposium Series 224, Volume 79, 1983, pages 46-50.

3-22. S. J. Brereton, "Explosion Hazard in Liquid Nitrogen Cooled Fusion Systems," Fusion Technology, 15, March 1989, pages 833-838.

3-23. W. G. Graham et a1., "Explosion Potential of Neutral-Beam-Source Cryopumps for TFTR," Proceedings of the Third Topical Meeting on The Technology of Controlled Nuclear Fusion, Santa Fe, New Mexico, May 9-11, 1978, pages 931-934.

3-24. R. R. Coltman et a1., "Techniques and Equipment Utilized in Low-Temperature Reactor Irradiation," Review of Scientific Instruments, 28, May 1957, pages 375-380.

3-25. W. B. Cottrel1, Ozone Explosion in Irradiated Cryogenic Apparatus and Implications upon N.S. Savannah Gaseous Waste Disposal System, ORNL Central Files Number CF-58-7-97, JuTy 24, 1958.

3-26. J. S. Loomis et a1., "Ozone Hazards Incurred by Electron Van de Graff Operation," Nuclear Instruments and Methods, 15, 1962, pages 243-248.

3-27. J. Romanko, Investigation of Explosions in Irradiated Liquid-Nitrogen Dewars, FZK-219, General Dynamics, December 15, 1964 .

3-28. W. V. Hassenzah1, office memo to T. Putnam, Los Alamos Scientific Laboratory, June 4, 1969. 
3-29. C. W. Chen and R. G. Struss, "On the Cause of Explosions in Reactor Cryostats for Liquid Nitrogen," Cryogenics, 9, April 1969, pages 131-132.

3-30. U.S. Department of Energy, Safety Performance Measurement System, identification code 3003502 , central file number 87718 .

3-31. U.S. Department of Energy, Safety Performance Measurement System, identification code 4006503, case number 89012.

3-32. C. Chiu et a1., "Depressurizing Analysis for Cryogenic Plant Safety," Cryogenic Processes and Equipment in Enerqy Systems, American Society of Mechanical Engineers, 1980, pages 57-60.

3-33. A. L. Schneider, "Liquefied Natural Gas Safety Research," Cryogenic Processes and Equipment in Energy Systems, American Society of Mechanical Engineers, 1980, pages 77-82.

3-34. E. C. Tanner, The First Princeton Tokamaks, 1970-1980, An Informal History, Princeton University Plasma Physics Laboratory, February 1982, pages 21-22.

3-35. P. I. Petersen et a1., "DIII-D Safety Procedures and Operational Experience," GA-A19687, presented at the IAEA Technical Committee Meeting on Selected Aspects of Fusion Reactor Safety, Jackson, Wyoming, April 3-7, 1989, preprint made available in June 1989.

3-36. P. L. Mondino, "The JET Power Supplies: A Review After One Year of Operation," Proceedings of the 13th Symposium on Fusion Technology, Varese, Italy, September 24-28, 1983, pages 119-131.

3-37. H. L. Darling, "Insulation Fire on a Storage Sphere," Safety in Air and Ammonia Plants, 9, 1967, pages 16-17.

3-38. J. Moorhouse and P. Roberts, "Cryogenic spill protection and mitigation," Cryogenics, 28, December 1988, pages 838-846.

3-39. W. I. Moore and R. J. Arnold, "Failure of Apollo Saturn V Liquid oxygen Loading System," Advances in Cryogenic Engineering, 13, 1967, paper J-1, pages 534-544.

3-40. F. S. Howard, "Geysering Inhibitor for Vertical Cryogenic Transfer Piping," Advances in Cryogenic Engineering, 18, 1972, paper D-4, pages 162-169.

3-41. B. H. Winegar, "Partial Collapse of an Atmospheric Ammonia Storage Tank, "Ammonia Plant Safety (and related facilities), 22, American Institute of Chemical Engineers, 1980, pages 226-230.

3-42. J. Prijatel, "Accidental Venting of Liquid Ammonia," Plant/Operations Progress, 2, April 1983, pages 131-136.

3-43. M. E. Sweat, "An Ammonia Tank Failure," Plant/Operations Progress, 2, Apri1 1983, pages 114-116. 
3-44. C. -F. Shih and C. D. Babcock, "Buckling of $0 i 1$ Storage Tanks in SPPL Tank Farm During the 1979 Imperial Valley Earthquake," ASME Journal of Pressure Vessel Technology, 109, May 1987, pages $249-255$

3-45. T. Hiro-oka, "Latest Design Features and Operational History of LNG Inground Tanks at the Negishi LNG Receiving Terminal," Advances in Cryogenic Engineering, 27, 1981, pages 937-944.

3-46. D. Robinson, Manager of Culham Laboratory Tokamak Operations Division, private conversation, JuTy 27, 1990.

3-47. R. Savercool, DIII-D/GA Technologies Safety Engineer, private conversation, November 7, 1990.

3-48. J. Hess et al., "Fabrication of stainless steel dewars for experiments at low temperature," Cryogenics, 17, September 1977, pages 501-507.

3-49. J. B. Czirr and R. J. Thome, Experience with Magnetic Accidents, Phase III Report, MESA Corporation, March 7, 1985, page 19. 


\section{Potential Safety Concerns with Cryogenic Fluids}

There are several features of cryogens used in fusion that present potential safety concerns for facility operations. These features or qualities are discussed in this chapter. Briefly, these potential safety concerns are: extreme cold effects on the surrounding environment, phase change pressurization effects and the possibility of personnel asphyxiation, safety of the warm gas handling plant, concerns from contaminants, large cryogenic liquid or gas releases to the environment, arld dielectric breakdown of helium and nitrogen. I will address each of these areas here. In addition, there are five sources of information on cryogenic safety that are very good references. These are ctted as references 4-1 to 4-5. There are also several excellent papers that outline the basic safety concerns with these fluids, cited as references $4-6$ to $4-9$.

\subsection{Introduction to Potential Safety Concerns with Cryogenic Fluids}

There are several possible safety challenges and concerns that can arise when using cryogenic fluids that have not occurred as operational problems or large accidents. There are other concerns that have been realized through their occurrence. All of these concerns must be addressed in some form of safety assessment or analysis for a future cryogenic system. Personnel safety issues have not been directly addressed among these safety concerns.

Safety concerns that have not occurred but should be analyzed are dielectric breakdown in the superconducting magnets, confinement building pressure responses to large release events, and local effects of cryogen leaks near the tokamak. These are addressed in the given order in the following subsections.

System safety concerns that have occurred are contamination, large spills to the environment, warm gas handling plant accident everits, and safety concerns over cryoplant noise levels. I discuss safety issues for these topics in the following sections. 


\subsection{Dielectric Breakdown Through Cryogentc Gases}

When cryogenic hellum or nitrogen is used to cool superconducting magnets, there is a concern that a fallure event inight allow the liquid coolant to warm up, change to gaseous phase, and allow an electric arc to form between magnet leads or the coils in a magnet. There are several sources of information on breakdown voltages needed for sustaining arcs in helium and nitrogen. $4-10$ to $4-15$

Breakdown voltage is a function of gas pressure. The breakdown strength for helium, from Levitov et a1., ${ }^{4-12}$ for cold helium gas at densities above $30 \mathrm{~kg} / \mathrm{m}^{3}$ and pressures between 0.4 and $1.0 \mathrm{MPa}$, is over $200 \mathrm{kV} / \mathrm{cm}$. Gerhold $\mathrm{d}^{4-14}$ gives the Paschen curves for helium and nitrogen, showing the relationship between gas density $x$ breakdown gap distance to the minimum required breakdown voltage. Nitrogen gas has its lowest breakdown voltage of about $4 \mathrm{kV}$ at about $2 E+22$ molecules $/ \mathrm{m}^{2}$. These values are for clean surfaces. Fusion magnet surfaces should be clean and free of any greases or other foreign materials. Foreign materials will likely decrease the given breakdown voitages.

Intuitive design suggests more solid insulator use, such as mylar or kapton, in regions of high voltage difference or in close proximity to chamber walls for fusion magnets. The mylar sheets, fiber epoxy resin, kapton, or other electrical insulation can be used to reduce the possibility of electric arc occurrence if the system has an off-normal event - perhaps a magnet quench - that causes cryogenic helium or nitrogen to change phases to gas and also drives voltages up to high values. When there is no clearance for extra insulation or if radiation effects have decreased the insulation value, smooth surfaces (no point discharge locations) and provision to keep cryogen temperatures low will help reduce the chance of arc initiation.

Another concern about arc formation is impurities or foreign materials in the cryogenic fluid. Jaksts and Mazurek ${ }^{4-16}$ have studied the ability of breakdown between two plates in a flowing LN2 stream when tungsten particles are introduced in the fluid. The voltage difference they applied between the plates is much larger than the voltage between 
pancake colls for large, toroidal fusion magnets $(100 \mathrm{kV}$ in the experiment versus a few hundred volts in magnet ramp-up; superconducting magnets should have only a few volts difference between pancakes while in steady state operation), however, this concern should be addressed in the magnet or cryogenic system design. An unidentifled foreign material did cause a short circuit in one of the Tore Supra torotdal field coils. ${ }^{4-17}$

Some foreign materials may not contribute to electrical breakdown between magnet pancakes, but they can restrict coolant flow. Fllters should be used to capture impurities in the magnet coolant. Even though such filters can plug up, they should be employed to prevent possible breakdown in off-normal magnet situations (when pancake cotl to pancake coti voltages can become quite large) and debris accumulation in inaccessible locations within the magnets or cryopanel piping. Filters can be placed away from the machine, so that they have the advantage of being accessible for hands-on maintenance or replacement.

\subsection{Confinement Building Pressure Responses to Large Cryogen Spi11s}

If significant quantities of liquid helium or liquid nitrogen escaped, the surrounding air would be cooled, and the building internal pressure would initially decrease. Provisions for building pressure fluctuations must be made to assure that confinement building integrity is maintained. While most thick-walled (2 $\mathrm{m}$ and larger) confinement buildings can withstand modest internal overpressure, perhaps on the order of $35 \mathrm{kPa}$ above atmospheric pressure, ${ }^{4-18}$ special design considerations need to be made for internal underpressure much below $101 \mathrm{kPa}$. Confinement building penetration seals and door seals should be examined for response to underpressures. This must be a consideration for the building design. An unpublished calculation for a total magnet cooling system liquid helium release from the Fusion Engineering Device showed that the $1 \mathrm{E}+05 \mathrm{~m}^{3}$ building air pressure decreased from near atmospheric pressure to $84 \mathrm{kPa}$ in 2.5 minutes, then the pressure rose up to a maximum of $45 \mathrm{kPa}$ overpressure in one hour. 4.19 Some means of passive overpressure protection was required to prevent confinement building breach in such an event. Piet and Brereton discuss several means of passive confinement building overpressure protection. ${ }^{4-20}$ 
Releasing cryogens will cause heat transfer from whatever they contact. The liquids will boll very quickly and then begin to pressurtze. At atmospheric pressure, and room temperature (about $295 \mathrm{~K}$ ), nitrogen has a gas to liquid volume ratto of about $700: 1$, and helium has a ratio of about $600: 1$. $^{4-21}$ Fortunately, future fusion facilities w111 be large - they must incorporate a large 'lay down' area to work on parts and the building will also be tall to provide heavy crane lifting cleararce for replacing torus sections or toroldal field magnets. While detrimental to costs, this extra air space and the thick walls for radiation shielding allow for large cryogenic fluid/gas releases without overpressurizing the confinement butlding. Sizing cryogenic systems so that entire inventory releases would not ifft the confinement building pressure relief valves would be a conservative safety design approach. A special concern to be treated for cryogenic gas releases is that the humidity in air does not freeze on pressure relief valves or other pressure relief devices, holding them open after the pressure ts relieved.

There are several safety concerns with these lirge cryogen releases. First, a cryogenic overpressure could mobilize any radioactive isotopes in the building, such as neutron activated air, tritium gas, volatilized neutron activation products, or tokamak dusts. For example, if liquid helium was released due to a magnet movement that sheared lines open and breached the vacuum vesse1, then tritium and tokamak dust might be lofted and expelled from the torus hall to the crane hall, and then to the atmosphere, if the building overpressure relief valves opened. ${ }^{4-14}$ The cold gas would also help to keep the radioactive isotopes initially near the ground. As the gas warmed in air, perhaps on the order of minutes, the isotopes would be lofted. Mixed cryogen and radioactive releases will likely have higher site boundary doses than room temperature radioactive releases. This cold effect must be analyzed to verify if standard dose calculation methods can be conservatively used for cryogenic spill-driven releases.

Another safety concern is personnel protection. With a cold gas cloud contained in the bullding, there is a hazard that unprotected personnel might enter the oxygen-diluted atmosphere. There is a fairly narrow band of acceptable oxygen concentration for humans, and while helfum will rise 
In atr, enough helfum trapped in a chamber will still present a real threat. ${ }^{4-22}$ The breathable air gutdelines in the us are a mintmum of $18 \%$ oxygen by volume $e^{4-23}$ and no prolonged exposures above $50 \%$ oxygen. ${ }^{4-24}$ Also, oxygen should not exceed $23 \%$ by volume due to concerns for much easter ignition of fires, ${ }^{4 \cdot 25}$ especially near electrical equipment.

\subsection{Effects of Cold Temperatures on Surrounding Structures}

Normally, liquid helfum (LHe) piping or storage for fuston applications has a liquid nitrogen (LN2) refrigerating shield within the insulating vacuum space to further reduce heat transfer into the LHe. Therefore, we have leakage concerns for hellum and nitrogen. If liquid hellum were to leak out into the vacuum space, heat transfer from the ambient atr would greatly increase, and there could also be condensation and even air liquefaction on the outer wall of the piping or storage vessel. This liquefied air would drip off the piping or vesse1. A danger is that the nitrogen in this liquid air would evaporate first, leaving oxygen rich liquid behind. This is a fire hazard, as well as a heat transfer (inleakage) problem for the original liquid helium system. 4-1,4-26 Gutters or catch pans should be used to route away any dripping liquefied atr to safe locations for vaporization.

If 1 iquid nitrogen or liquid helfum were to escape from the cryogenic piping, any mild (carbon) steel cooled down by impingement or immerston would become brittle due to its body-centered cubic structure nil-ductility transttion. ${ }^{4-27}$ Therefore, no equipment near - above or below - the cryogenic lines should be butlt with carbon steel or any other material that embrittles at low temperatures. This includes the vessel supports, pipe hangers, cable trays, and any cooling water lines.

Heat removal from surrounding structures poses a safety concern. Even stainless steel has contraction under LHe cold, on the order of 2.7 inn per meter. This contraction is significant. Thermal contraction has forced designers to use metal bellows, flexible lines, and a variety of pipe lienu configurations so that temperature-induced flexure does not overstress the pipelines. Contraction could also occur to copper electrical lines 
exposed to extreme cold, and electrical insulation could become brtttle. Therefore, plasma diagnosttcs and control system wiring could be at risk when placed near cryogentc lines. Electrtcal insulation might become brittle after cryogen exposure, causing a decrease in ths $11 \mathrm{fe}$ and possibly increasing the probabilitiy of short circutts and fires.

Another concern over extreme cold temperatures is that prolonged exposure of water piping to cryogentc flutd or to very cold gas could cause ice formation in the plping. Ice could plug the lines, or the thermal shock to the $393 \mathrm{~K}(120 \mathrm{C})$ and higher piping being exposed to $77 \mathrm{~K}$ or $4 \mathrm{~K}$ cold gas, could lead to fracture. With the combination of sudden contraction stresses and possible pipe plugging, the pipes may not fail, but this would lead to the suspicion of decreased service life and then early piping changeout. If a cooling line ruptured, it would compound the already occurring magnet cryogen leakage accident. I have noted that the Canadian fission reactors use a LN2 cooling jacket to freeze plug stagnant deucerium oxide coolant lines for maintenance work. ${ }^{4-28}$ If a cryogen, such as LN2, leaks during machtne scheduled downtime (perhaps the nightly shutdown), any nearby water coolant lines would probably be freeze plugged the next inorning. If the ITER cooling water plping is insulated, then the heat transfer from the cryogentc gas is reduced and more time is then avallable to allow the cryogentc gas to warm up in the ambient environiment. 4-26 Piping insulation for crittical areas around the tokamak is a conservative safety idea, although it would hamper remote video camera visual inspections and perhaps remote maintenance, and might increase the amount of low level waste to be disposed of. This safety trade-off must be examined during the ITER Engineering Design Activity.

\subsection{Cryogen Contamination concerns}

Contamination of the liquid cryogens is a concern for several reasons. First, the contaminarits, either gases or solids, can plug up a magnet conductor conduit, causing magnet localized overheating. Plugs can also form in the cryogenic itnes themselves, causing loss of flow events. Next, the contaminants can become activated, and if they circulate around the cryogenic system, mainteriance could become difficult. Another reason is the concern over chemical reactions. 
If oxygen liqueftes in LN2 or LHe, there is a small posstbiltty that it will be an oxidant. Systems for itquid oxygen (LOX), prillarlly in the aerospace industry, have experfenced such events. Tests of centrifugal pump responses to pressure decreases (small breach events) in Lox systems showed pump impellers partially consumed in LOx fires. 4-29,4-30

other industries have also noted the posstbiltty of bad pump bearings overheating the aluminum impeller and causing aluminum-refrigerant reactions. These reactions can be forceful enough to fracture the Impeller and breach the pump casing. 4-31 oxidant reactions are a small concern compared to another problem with oxygen intrusion into d fusion system.

When the amount of oxygen dissolved into LN2 is high, 20 ppm or more, gamina or neutron radiation fields are likely to cause ozone creation. Several events of this type, with ozone or nitrate explosions occurring, happened in the 1960 's, as discussed in Chapter 3 . In fact, Chapter 3 also discusses two more probable ozone explosion events in the US in the $1980^{\prime} \mathrm{s}$. While oxygen would freeze at L.He temperatures, (freezing point is $55 \mathrm{~K}$ at 1 atmosphere pressure), it st 111 flows at LN2 temperatures. However, if atr leakage into LHe, or even small air leakage into the insulating vacuum, is near the source of radtation, ozone can still be created in frozen oxygen. Ozone freezes at $80 \mathrm{~K}$ at atmospherits pressure, so LHe or LN2 will freeze it out near where it is created, allowing it to accumulate on magnet or neutral beam refrigerating shields, or in cryotraps. The best known means of suppressing ozone formation is to use very high purity cryogens. LN2 with oxygen concentrations of less than 10 ppm has been used without incident in low level gamma irradiation fields, ${ }^{4-32}$ although 5 ppm or lower is recommended for safety in higher irradiation fleld fusion experiments. ${ }^{4-33}$ other ideas to reduce the ozone threat are to warm and purge the system, thus sweeping out ozone, or use filters to trap any circulating ozone. Unfortunately, system purging to sweep out ozone may not be practical for some systems, and additional filters increases the risk of line plugging. 


\subsection{Modelling Large Cryogen Spills to the Environment}

Most cryogentc systems matntain a reserve supply of cryogenic flutd, on the order of tens of thousands of liters, for peak demands. In the case of fusion, perhaps a magret quench would require a reserve of L He for recooling the magnet, purging a system with cool gas for pre.cooling, or other operational demands. Storage tanks for cryogens present a safety concern. In Chapter 3, we saw that several cryogenic storage tanks have leaked their contents to the environment, and that the chemical industry has had many public evacuations for cold or toxic gas releases. The ammonia treatment industry for agricultural fertilizers, liquefted natural gas energy utiltties, and aerospace industrtal concerns have all analyzed the problem of releasing a cryogentc liquid or gas cloud over 1 and and on water. 4-34 to 4-4? These approaches use the typlcal gausstan plume modeling, treating heavter than air gases. Since these clouds are gerierally heavier than air, even refrigerated ammonia, the models are applicable to LN2. LHe has the advantage of being lighter than air and is not considered a threat if released outdoors. Sinall LHe clouds have been seen to initially settle because of their cold temperature, then very quickly rise again as they warm in air. ${ }^{4-26}$

A release of $L N 2$ from a storage tank, because of a fire, impact event, overpressurtzation, earthquake, or for any other reason, would likely form a "pancake cloud" shape until it warms. This slumped gas cloud shape is characteristic of a heavier-than-air gas or cryogenic temperature gas release. ${ }^{4-41}$ Site specific analysis would have to be performed to understand the safety implications of a release of a simple asphyxiant gas such as nitrogen. If radioactive isotopes are entrained in the cryogentc cloud, the gas warmup time to allow lofting would greatly affect the radiological dose at the site boundary. Many of the sophisticated models for heavy gas plumes, such as the DEnse CAs DISpersion (DEGADIS) computer code, ${ }^{4-41}$ assess the potential for gas cloud explosions rather than simple asphyxiation. Wind speed, air temperature, location of site building ventilation air intakes relative to the release point, and distance to public habitations must be considered in such an analysis. Proposed $1 \mathrm{~km}$ site boundaries for future fusion facllities would likely provide enough distance for turbulent mixing in air to protect the public 
from any detrimental effects of a large LN2 release, but this should be verlfled. Support bulldings on the fuston factlity stte must be protected from nitrogen gas entry into their ventilation systems. Another important safety tip is to have more than one access road into and out of any facllity, so that if a plume of any kind is released (tritlum gas, LN2, smoke from a fire, etc.), evacuating personnel or incoming rescue personnel have two options avatlable to try to avold the plume rather than be forced to drive through it. Multiple roads are generally considered to be a securtty probiem, but it is very important to personnel safety to have at least two evacuation roads in different directions.

\subsection{Gas Handling Plant Safety}

In most cryogentc systems, there are warm (room temperature) gas handling requirements. For example, nitrogen plants generally begin by compressing air and then separating the components. Some systems must deal with botloff gases. Fusion factlities have to have provistons for gas bolloff in case of a magnet quench event. There are several safety concerns for the gas handling plant. These plants, such as for liquefying nitrogen, can handle high pressure, high temperature gas. The same safety concerns for personnel exposure exist, with the additional concern for explosions. Pressurtzed systems can be qutte hazardolls. A study of simple 0.3-m diameter, 1.4-m tal1, 14-MPa gas storage cylinders showed that breaking the valve off of a given cylinder allowed tt to become a missile, crash through two standard construction brick walls, and remain airborne for some distance before stopping, 4.13 There are concerns that the plant might expertence energetic explostons in the compressor or storage tanks, due to air inleakage or hydrocarbon contamination. older information indicates that compressors have had explosions and fires due to lubricating $011 \mathrm{~s},{ }^{4.44}$ and Chapter 3 gave some compressor fire events. Forceful explostons could easily damage nearby equipment, such as electrical power lines, cryogenic liquid storage tanks, or other facility support systems (instrument air bullding, cooling water pump house, etc.). Pipe whip from broken high pressure lines could also be a problem. Fortunately, fusion facilities use only helium and nitrogen as cryogenic gases, not explostve gases such as hydrogen, oxygen, ammonia, 
propane, or natural gas. The component failure rate section gives values for some equifment in the warmed gas plant as well as cryogenic components.

\subsection{Noise Protection for Cryogenic Systems}

Noise in the gas handling plant is also a personnel health and safety concern. Modern ammonia gas handling plants can generate around 100 decibeis near large compressors, ${ }^{4-45}$ and I assume that nitrogen and helium compressors produce comparable levels. To put this in perspective, a turbofan jet engine, with acoustic ireatment, generates only a few decibels higher noise level on takeoff. ${ }^{4-46}$ Noise and vibration must be considered in cryogenic system design and in the system's location within a fusion facility.

There are probably other cryogenic safety concerns not mentioned here. Designers and safety analysts must thoroughly assess the systems for fusion magnet cooling, cryopump cooling, and radiation detector cooling at future fusion facilities.

\subsection{Special Cryogenic Safety Issues to Examine for Future Facilities}

Future fusion experiments, such as ITER, will use large amounts of LN2 and LHe. Therefore, the safety issues discussed here must be examined during an ITER safety assessment. The straightforward issues of cryoplant availability and large cryogenic accidents, loss of coolant and loss of flow, must be analyzed. Of the potential safety concerns discussed here, the issue of radioactive isotopes entrained in a large cryogen release initially being held closer to the ground because of the cold gas cloud requires particular attention. The issue of a small overnight cryogen leak causing water coolant line freezing, electrical cable degradation, or structural support overstress should also be examined. The effects of a $1 \mathrm{~km}$ site boundary on large LN2 releases must also be verified. 
4-1. K. D. Williamson, Jr., and F. J. Edeskuty, Liquid Cryogens, volume 1, Chemical Rubber Company, Boca Raton, Florida, 1983, Chapter 1.

4-2. M. G. Zabetakis, Safety with Cryogenic Fluids, Plenum Press, New York, 1967.

4-3. Safe Handling of Cryogenic Fluids, CGA P-12, Compressed Gas Association, 1987.

4-4. Cryogenics Safety Manual - A Guide to Good Practice, British Cryogenics Council, Mechanical Engineering Publications, London, United Kingdom, 1982.

4-5. R. B. Scott et a T., Technology and Uses of Liquid Hydrogen, MacMillan Pergamon Press, 1964.

4-6. G. H. Zenner, "Safety Engineering as Applied to the Handling of Liquefied Atmospheric Gases," Advances in Cryogenic Engineering, 1, 1960, paper H-5, pages 291-295.

4-7. K. D. Timmerhaus and T. M. Flynn, "Safety with Cryogenic Systems, "Advances in Cryogenic Engineering, 23, 1977, paper R-2, pages $721-729$.

4-8. M. G. Zabetakis, "Hazards in the Handling of Cryogenic Fluids," Advances in Cryogenic Engineering, 8, 1963, paper E-1, pages 236-241.

4-9. R. 0. Ormsby, "Process Hazards Control at Air Products," Plant/Operations Progress, 1, July 1982, pages 141-144.

4-10. A. Kawashima, "Electrode area effect on the electric breakdown of 1 iquid nitrogen," Cryogenics, 14, Apri1 1974, pages 217-219.

4-11. R. A. Haarman and K. D. Williamson, Jr., "Electrical Breakdown and Tracking Characteristics of Pulsed High Voltages in Cryogenic Helium and Nitrogen, " paper B-6, Advances in Cryogenic Engineering, 21, 1975, pages 102-108.

4-12. V. I. Levitov et a1., "A Study of Electric Discharges in Helium at Low Temperatures," IEEE Transactions on Magnetics, MAG-13, January 1977, pages 166-171.

4-13. H. Fujita et a1., "Breakdown voltages of gaseous $N_{2}$ and air from normal to cryogenic temperatures, "Cryogenics, 18, April 1978, pages 195-200.

4-14. J. Gerhold, "Dielectric breakdown of cryogenic gases and liquids," Cryogenics, 19, October 1979, pages 571-584. 
4-15. J. Gerhold, "Breakdown Phenomena in Liquid Helilim," IEEE Iransactions on Electrical Insularion, 24, April 1989, pages $155-166$.

4-16. A. Jaksts and B. Mazurek, "Particle initiated flashover in liquid nitrogen," Cryogenics, 30, January 1990, pages 68-71.

4-17. D. Bessette et al., "Story of Damaged BT 17 Coil of the TF Superconducting Magnet of Tore Supra," Fusion Technology 1990, Proceedings of the 16th Symposium on Fusion Technology, London, UK, September 3-7, 1990, pages 1659-1663.

4-18. D. F. Holland et a1., Potential Off-Normal Events and Releases for the Burning Plasma Experiment, EGG-FSP-7872, revision 3, July 1991 , pages $49-51$.

4-19. J. L. Jones and B. J. Merrill, "Building Overpressure from Cryogenic Release," INEL unpublished report, 1982.

4-20. S. J. Piet and S. J. Brereton, Fusion Radioactivity Confinement and Application to Postulated ITER Accidents, EGG-FSP-9470, EG\&G Idaho, Inc., March 1991.

4-21. R. E. Bolz and G. L. Tuve, Handbook of Tables for Applied Engineering Science, Chemical Rubber Company, Boca Raton, Florida, 1983, page 590.

4-22. D. P. Brown and J. H. Sondericker, "Oxygen Deficiency Hazard Induced by Helium Release in Accelerator Tunnel, "IEEE Iransactions on Nuclear Science, NS-30, August 1983, pages 2898-2900.

4-23. 1990-1991 Threshold Limit Values for Chemical Substances and Physical Agents, and Biological Exposure Indices, American Conference of Governmental Industrial Hygenists, Cincinnati, Ohio, 1990.

4-24. A. J. Finkel, Industrial Toxicology, John Wright Publishers, Boston, Massachusetts, 1983, page 187.

4-25. Compressed Gas Association, Safety and Accident Prevention in Oxygen Deficient and Oxygen Enriched Atmospheres, CGA-P-14, 1983.

4-26. H. J. Welland and G. A. Thorsen, EG\&G Idaho, Inc., cryogenic system designers, private conversation, November 21, 1991.

4-27. R. F. Barron, Cryogenic Systems, Oxford University Press, New York, 1985, pages 13-18.

4-28. K. Y. Wong et al., Canadian Tritium Experience, Ontario Hydro, 1984, pages 23-24.

4-29. H. Bauer et al., "Fire Tests on Centrifugal Pumps for Liquid oxygen," Cryogenics, 10, June 1970, pages 241-248. 
4-30. H. Bauer et al., "Fire Tests on Centrifugal Pumps Handling Liquid Oxygen - Part 2," Cryogenics, 11, December 1971, pages 469-476.

4-31. R. Stevens, "A Couple of Unusual Occurrences," Plant/Operations Progress, 4, April 1985, pages 68-71.

4-32. J. Johansson, "High Purity Nitrogen Cooling System of an In-Core Irradiation Cryostat for a TRIGA Mark II Reactor," paper E-9, Advances in Cryogenic Engineering, 21, 1975, pages 237-241.

4-33. S. J. Brereton, "Explosion Hazard in Liquid Nitrogen Cooled Fusion Systems," Fusion Technology, 15, March 1989, pages $833-838$.

4-34. C. P. Guldemond, "The Behavior of Denser than Air Ammonia in the Presence of Obstacles - Wind Tunnel Experiments,"

Plant/Operations Progress, 5, Apri1 1986, pages 93-96.

4-35. G. D. Kaiser and B. C. Walker, "Releases of Anhydrous Ammonia from Pressurized Containers - The Importance of Denser-than-Air Mixtures," Atmospheric Environment, 12, 1978, pages 2289-2300.

4-36. W. G. May et a1., "Dispersion of LNG Spil1s," Hydrocarbon Processing, 52, May 1973, pages 105-109.

4-37. D. N. Gideon and A. A. Putnam, "Dispersion hazard from spills of L.NG on land and on water, " Cryogenics, 17, January 1977, pages 9-15.

4-38. G. Opschoor, "Investigations into the spreading and evaporation of LNG spilled on water, " Cryogenics, 17, November 1977, pages $629-633$.

4-39. M. P. Singh et al., "Estimation of Vulnerable Zones Due to Accidental Release of Toxic Materials Resulting in Dense Gas Clouds," Risk Aricilysis, 11, 1991, pagt's 425-440.

4-40. G. Opschoor, "Investigations into the evaporation of liquefied gases spreading on land," Cryogenics, 21, May 1981, pages $281-286$.

4-41. H. R. Greenberg and J. J. Cramer, editors, Risk Assessment and Risk Management for the Chemical Process Industry, Van Nostrand Reinhold, New York, 1991, Chapter 10.

4-42. R. C. Reid and R. Wang, "The boiling rates of LNG on typical dike floor materials," Cryogenics, 18, July 1978, pages 401-404.

4-43. R. H. Guymon et al., Safety Implications Associated with In-Plant Pressurized Gas Storage and Distribution Systems in Nuclear Power Plants, NUREG/CR-3551, Oak Ridge National Laboratory, May 1985.

(See also: R. H. Guymon, Nuclear Safety, 27, April-June 1986)

4-44. J. J. DiNunno, "Explosions and Fires in Compressed-Air Systems," Nuclear Safety, 2, September 1960, pages 44-49. 
4-45. D. T. Cindric and M. J. Hassett, "Noise in Ammonia Plants: A Twenty -Year Perspective", Ammonia Plant Safety (and related $\frac{\text { facilities) }}{\text { pages } 41-48}$. 29, American Institute of Chemical Engineers, 1989,

4-46. J. F. Groeneweg and E. J. Rice, "Aircraft Turbofan Noise, "ASME Journal of Turbomachinery, 109, January 1987, pages 130-141. 


\section{Suggested Fallure Rates for Cryogenic Components}

This chapter describes selection of suggested fallure rates for cryogenic liquid and gaseous system components. These failure rates can be applied to specific systems designs to develop system reliabllities, unavailabilities, or can be used for probabllistic risk assessment calculations. Fault tree analysis, quantified with component fallure rates, is the primary tool for modeling systems to obtain their unavailabilities. More accurate component failure rate values might he. obtained from manufacturers when a fusion design progresses further.

The failure rates described here are generally taken from failure studies of similar equipment, mainly from LNG plants and particle accelerator LHe systems. Reported failure rates are usualiy given for mature equipment that exhibits reasonably consistent behavior; therefore, the reported failure rates are constant values. This means that all early failures, such as 'burn-in' or 'break-in' faults, manufacturing defects, assembly errors, installation errors, chemical/physical contamination of materials, use of substandard materials, poor workmanship, etc, have not been included in the analys is to generate the failure rates. The classical "bathtub curve", as shown in Figure 5-1, applies to components in this chapter. The figure shows a plot of failure rate versus operating hours, where the early failure rate is initially very high and decreases with time, then levels out to a practically constant value for the chance failure rate over the majority of component operating life, and finally the wearout failure rate increases with time in the end of life region. ${ }^{5-1,5-2}$

Chance failures might be caused by insufficient safety factors, stress or strain conditions that exceed the design envelope, potential human errors in operations, and component misapplications. Wearout failure causes might be material wear, fatigue, creep, corrosion, general deterioration, a life of poor maintenance, or a short design life. ${ }^{5-1}$ The failure rates presented in this chapter are chance, or random, values over the useful component operating life. Error factors or conservative upper bounds on the failure rates are given whenever possible. If the failure rate itself is an upper bound, then that fact is stated. 
Fallures due to Early and Random causes

Fallures due to Random oauses only (Such failure rates are given In this ohapter)

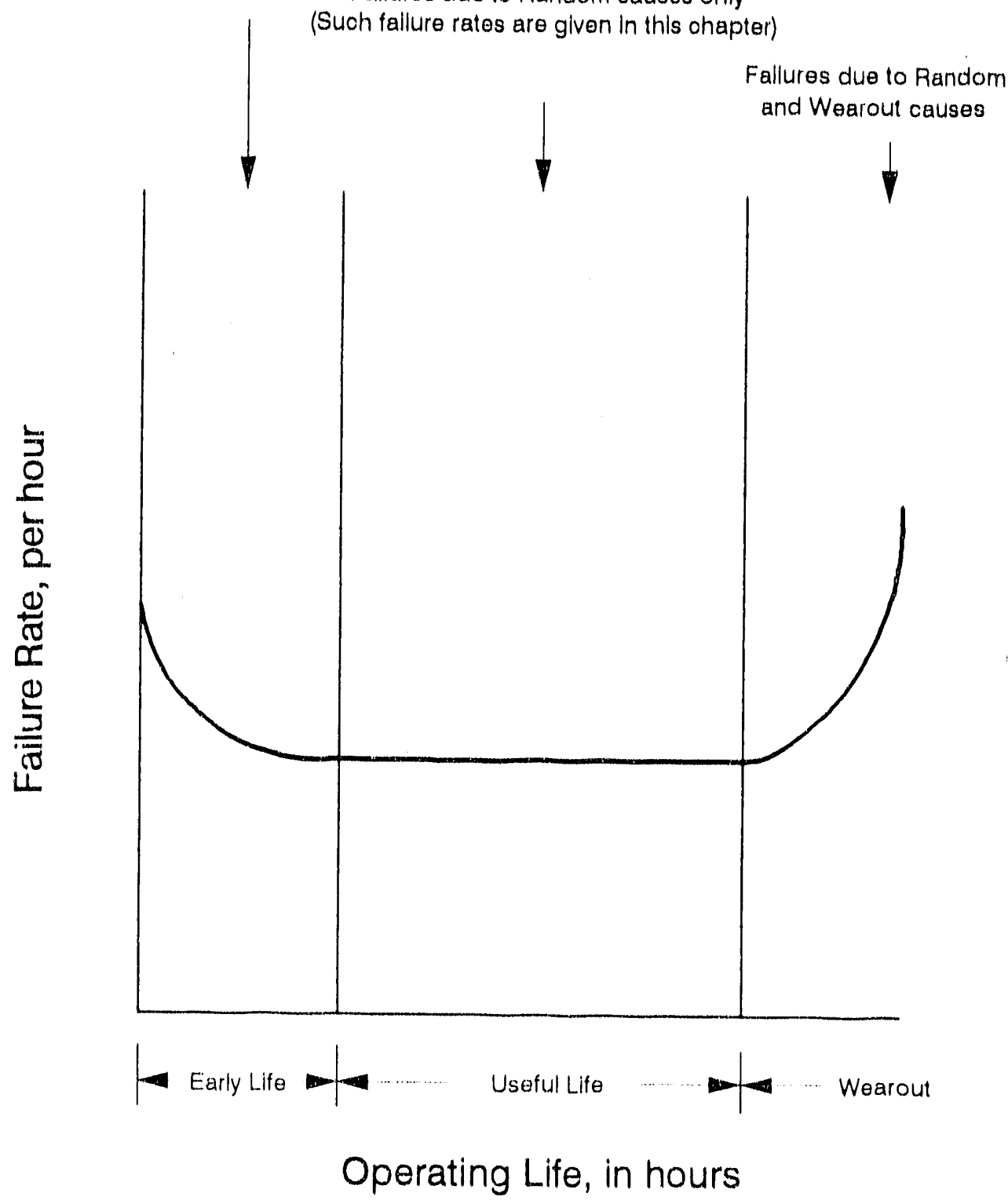

Note: Early life should have testing and $Q A$ Useful life should have D-T operations, before wearout

Figure 5-1. The reliability bathtub curve.

(Taken from reference 5-1.) 
If analysts choose to use these fallure rates for risk or availability assessment, then they are implicitly assuming that there have been rigid quality assurance and pre-operational testing programs to eliminate the early or 'burn-in' fallures. They are also assuming that there is an adequate design margin in the equipment to provide a long life span, such that wearout failures are not encountered during facility operation, just like the design life of most of the equipment chosen to draw analogies to these fuston cryogenic components.

I have not addressed common cause or dependent failures in this chapter. Many of these fallures are highly influenced by the fusion reactor design and spatial layout. Common causes, especially those from cold cryogen release, must be treated when adequate design information is avallable. Generally, many common causes can be approached using the standard Beta factor methods and some by explicit modeling, such as for internal floods and other consequential events. ${ }^{5-3}$ Some human error probabilities for initiating event modeling are discussed in the next section.

To give the reader some insight as to the approximate regions of the early, useful, and wearout life spans, I have an example from the 1iterature. A study of 22 newly started US commercial nuclear power plants showed that for the first testing period after initial criticality (startup), the inadvertent shutdown (scram) rate was a factor of 5 higher than for the 76 mature US nuclear plants. The number of inadvertent shutdowns can be considered to be an indicator of plant safety, with fewer inadvertent shutdowns generally meaning higher safety and better operations. Some of these new plants averaged less than one inadvertent shutdown each month. A US commercial nuclear power plant might be in pre-operational testing after initial criticality for periods on average of 8 months, while a few plants have taken two or more years. The new plants study ${ }^{5-4}$ also showed that equipment forced outages caused an average 3 hours of downtime per 1,000 operating hours in the first quarter year after initial plant criticality. The equipment induced outages reduced to 0.5 hours of downtime per 1,000 operating hours by the beginning of the second year after initial commercial operation. The new plant study considered a mature plant to be over 4 years of the standard 
40 year power plant $11 \mathrm{fe} .^{5-4}$ Therefore, I consider the early $11 \mathrm{fe}$ for the power plant equipment to be on the order of 3-4 years (including the 8 months of testing), with inadvertent outages dropping by a factor of perhaps 6 in that 3-4 year time interval. Cryogenic systems would probably behave similar to nuclear plants, perhaps closer to 1 or 2 years of early iffe. Accelerator expertences with cryogenic systems show these 1-2 year times, and sometimes longer, for early system 1ife. The Large Col1 Task (LCT) magnet testing experience for a year showed that the problems with the cryogenic system, such as cryogen leaks, air inleakage, etc., were not fully resolved. ${ }^{5-5}$ Accelerator experiences also show that these systems require frequent maintenance, but not major component replacement. Life spans of 20 or more years are probably reasonable for cryogenic systems, with good maintenance and operational practices. Accelerator experiences show that factors of 2 to 3 or greater reductions in early life to useful life failure rates are possible for major components. Since future fusion experiments will have phased missions, by the time tritium operation is reached, the systems should be operating at their constant value failure rates.

Some of the fallure rates given here are taken from accelerator helium system experiences, some from liquefied natural gas (LNG) experiences, and some are estimated values. Cryogenic systems for each of these gases, helium, nitrogen, or $L N G$, have their own types of liquefaction systems, based on the ease or difficulty of liquefaction. Helium gas is usuali $j^{\prime}$ compressed in a large compressor, usually either a reciprocating or screw type unit, then expanded in one or more reciprocating expansion engines (large scale applications, in the hundreds of tons per day range, use turboexpanders). Heat exchangers, usually plate and fin units, are used to remove unwanted heat from the gas, then the gas is further depressurized by a Joule-Thompson (J-T) expansion valve into a reservoir. The effluent from the J-T valve is part liquid and part gas. A wet expander or expansion engine is used instead of, or in parallel with, a J-T valve for some magnet cooling systems, perhaps the 5,000 1iter/hour size and larger. Any cool gas exhausted with the product helium resides in the upper region of the storage tank until it is circulated back into the process stream. Pre-cooling the system with LN2 can decrease the number of components or, more likely, the time required to produce a given 
volume of LHe. ${ }^{5-6}$ For turboexpanders of less than $37 \mathrm{~kW}$ (50 horsepower), a dynanometer can be used to dissipate the shaft energy obtained from the gas expanston. For larger powers, electric generators, pumps, blowers, or integral compressor loads are usually used. ${ }^{5-7}$

Some of the fallure rate information I am applying to fusion originated from LNG facilities. LNG systems are more complex due to the vartety of gases included in natural gas. In the US, LNG is mainly methane ( 85 to 95\%), but contains other gases, such as propane, that 7 iquefy at temperatures different from the freezing point of methane. A mixed refrigerant cascade system is most often used to liquefy natural gas. Compressors and J-T expansion valves are used to liquefy the component gases, expanding them down to cryogentc temperatures (about $110 \mathrm{~K}$ at atmospheric pressure). ${ }^{5-6}$

Large quantities of nitrogen are typlcally liquefied by a cascade system, similar to that first used to liquefy air in the 1930's. Several compressor steps with intermediate cooling by cold ammonia, methane, or freon refrigerant are used. A final J-T expansion valve lets a mixture of liquid and gaseous nitrogen down to a storage tank. The gaseous nitrogen is circulated back into the process stream. ${ }^{5-6}$ This LN2 cascade technique is efficient but expensive. Nitrogen is sometimes liquefied and sold as a byproduct of natural gas distribution plants, where LNG is warmed to back into gas for pipeline routing and distribution. ${ }^{5-8}$

I will examine major components individually. The main types of components treated here will be those just discussed, namely, reciprocating and turbo compressors, piping, reciprocating expansion engines and turboexpanders, heat exchangers, electric and pneumatic valves, pumps, storage tanks, and dewar-type vessels. Instruments for temperature, pressure, and flow rate measurement will be treated using data from other industries. Warm gas handling subsystem components, such as piping, storage tanks, compressors, gas cylinders, and instruments to deal with re-liquefying boiloff gases, or to make LN2 on-site, will also be examined. 


\subsection{Cryogentc Compressors}

These compressors are slightly different than those units that service needs such as power plant instrument atr or breathing atr. Compressors for cryogenic systems of our interest can be large (perhaps $1.5 \mathrm{MW}$ or larger), and compress gas up to moderate pressures (on the order of 20 atmospheres). These compressors may have several stages of compression with intercooling, followed by aftercooling, then oll removal and flltration.

Small reciprocating helium compressor (95 1iters/hour, 20 atmospheres pressure) experiences at Fermilab show that the compressor first stage has a mean time between major failures of 1,500 hours for the 48 units. The fallure rate is the inverse of the 1,500 hours value, if we assume small repair times (compared to the 1,500 hours). The second and third stages each have a mean time between fallures (MTBF) of 800 hours. Since this is a series unit, we add the fallure rates for each stage to get an overall compressor fallure rate of about 3E-03/operating hour. I note here that the authors of the accelerator papers are implicltly using the constant failure rate assumption when they give MTBF values. An interesting operations statistic is that using an LN2 heat exchanger to pre-chill the helium in the system can allow production of LHe within 10 hours of start up from room temperature. ${ }^{5-9}$

The Energy Doubler accelerator helium system compressor avaliability has also been discussed. For failures, the staff estimated that it would typically take 60 hours of downtime to repair the compressor (so a Mean Time to Repair, or MTTR, is 60 hours). When the redundant, standby unit was installed, they believed that an iristantaneous switchover to the standby unit could be performed with no system transient effects after primary unit failure. ${ }^{5-10}$

Literature for multi-stage reciprocating air compressors showed that failure rates are in the range of 4E-06/hour to $2 E-04 /$ hour. ${ }^{5-11}$ The larger units appear to be more relitable, according to the literature. This may be because larger units can more easily be run at partial speeds to meet nor-peak demands, reducing piston and piston seal wear. Major LNG 
compressor (both reciprocating and turbo units) system fallures have a MTBF of 19,000 hours, ${ }^{5-12}$ or a fallure rate of about $5 E-05 /$ hour, if repair titine is reasonably assumed to be much smaller than 19,000 hours. For the case of major gas explostons in the compressor, its downtime was reported to be between 3 and 6 days. Therefore, downtimes for less catastrophic events, perhaps more on the order of the 60 hours cited in the Fermtlab paper, are probably appropriate for a fuston compressor MTTR.

Given that reported reciprocating compressor fallure rates vary between $2 \mathrm{E}-04$ /hour to $3 \mathrm{E}-03 /$ hour, and itterature values for turbomachine compressors vary between $4 \mathrm{E}-05 /$ hour to $6 \mathrm{E}-05 /$ hour, ${ }^{5-11}$ I suggest a conservative fatlure rate of $3 \mathrm{E}-03$ /hour should be used for small rectprocating units and 1E-04/hour be used for for small turbo units. These values could easily vary by as much as a factor of 10 , so I assume an error factor of 10 . The error factor for a lognormal distribution value is the $95 \%$ upper bound fallure rate divided by the median fallure rate. For this rough approximation technique, I assume the error factor is about the same as the $95 \%$ upper bound divided by the average value.

\subsection{Cryogentc Piping}

Piping for cryogentc fluids is usually double-walled pipe that contains peritte or another thermal insulation in the annular space between the inner and outer pipes. LNG applications use perlite in a vacuum space, LHe applications would likely use aluminized mylar in a vacuum space. The annular space is also usually pumped down by some type of vacuum pump to low pressures, perhaps as low as $1 \mathrm{E}-03 \mathrm{~Pa}$, to further reduce heat transfer, espectally for L L at $4.5 \mathrm{~K}$. Short runs of LNG piping may be single walled pipe with external insulating layers of perlite, balsa wood, or even fiberglass insulation. Urifortunately, I find that typtcal water-cooled fission reactor piping fallure rates do not really apply for cryogenic pipes. Water reactor piping carries much higher pressures (up to $16 \mathrm{MPa}$ ) and is thicker walled. cryogentc piping is insulated and thin walled to reduce heat transfer from the system's heat source, such as the mayncts, to the fluid. Cryogenic pipe often has thin walls of $2.1 \mathrm{~mm}$ (schedule 5 ) or $3 \mathrm{~mm}$ (schedule 10).5.6 Pressurized water reactor plping is generally $5.5 \mathrm{~mm}$ (schedule 40) or 
$7.6 \mathrm{~mm}$ (schedule 80). Cryogenic piping is 1ikely to be 2 to 4 timies thinner walled than light water reactor piping, although both may be made of 300 sertes stainless steel. The LNG industry information is more acceptable for fuston cryugenlc system applications than light water reactor data, since the LNG materials are designed to be compatible with the temperature region (about $110 \mathrm{~K}$ at atmospheric pressure), and account for the special low heat transfer requirements. While light water reactor data is accessible and has a very large data set, the piping is not. simillar enough to apply these values to cryogenic systems. Another fact to consider is that light water reactor piping may be only carbon steel with stainless steel lining (cladding) rather than statnless steel throughout. Cryogentc piping is generally stainless steel or aluminum, and its fallure rate will vary from that of clad pipe. From I.NG experience, the plping fallure rate for major fallures (breaks or ruptures) is about 5E-9/hour-meter, for all dlameters. ${ }^{5-12}$ For minor fallures like small leakage, the piping fallure rate is about $6 \mathrm{E}-10 /$ hour-meter for all diameters. Another interesting experience from the LNG industry is that pipe insulation has expertenced many fallures such as cracking, moisture buildup in insulation, and insulation joint seal degradation. ${ }^{5-12}$

To compare the L.NG piping experience values with nuclear power plant piping fallure rates, for pipes greater than $76-\mathrm{mm}$ diameter, nuclear power plant pipe rupture failure rates are about $3 E-11 /$ hour-meter. ${ }^{5-13} \mathrm{~A}$ more recent study ${ }^{5-14}$ gave a fallure rate of $3 E-04 / p$ lant-year, or about 3E-12/hour-meter (assuming $12 \mathrm{~km}$ of piping per plant, see Appendix $D$ of reference 5-14). Compared to the 5E-9/hour-meter, factors over 1000 in liberalism are assumed when fusion analysts apply water piping fallure rates to cryogenic piping. Fortunately, cryogentc piping runs are usually short in length, so these variations in failure rates should not present extremely divergent results in risk calculations.

The fallure rates assumed here from LNG experience can serve as a basis for preliminary calculations. I recommend detalled calculations using the Thomas method ${ }^{5-15}$ for refined piping failure rate values. This method takes the wall thickness and number of welds into account, based on the idea that more material defects are present when there is 
more matertal and more welds. The base probability for the Thomas method multiplier approach should probably be increased an order of magnitude from the water piping value of $1 \mathrm{E}-09 /$ hour. For our purposes here, a small leakage fallure rate of $6 \mathrm{E}-10$ /hour-meter and a large leakage (rupture) fallure rate of 5E-9/hour-meter will suffice. Error factors of 100 should be applied to these values from the LNG database report, ${ }^{5-12}$ due to uncertainties in the LNG system information gathering process.

Bellows fallure rates can be set by the manufacturer's requirement on bellows 1 ife. If a bellows destgri lifetime is 7,000 exercises, ${ }^{5-16}$ and we assume no fatlures over its 1 if fetime, then a $50 \%$ chi-square distribution ${ }^{5-17}$ for zero fallures is $0.455 / 2(7,000)=3 E-05 /$ demand. An error factor of 8 or perhaps 10 , should be applied to this fallure rate. Many bellows with damage by scarring and dents st 111 meet their design life, but those repatred by welding have been shown to have life decreases down to $35 \%$ of original specifications. ${ }^{5-16}$ This fallure rate depends on the design life of the bellows under consideration.

Welds in the cryogenic plping should be as carefully made and controlled as those in a nuclear power plant because of the consequences of weld fallure. Nuclear fission grade ( $\mathrm{N}$-stamp) quality assurance may not be needed because helfum will not become radioactive, but high quality must be maintained for the cryogenic system. Buende $e^{5-18}$ has surveyed weld reliability for fusion blankets and determined average leakage fallure rate values to use for various types of welds. These values should apply to cryogents systems as well. For longitudinal welds, about 6E-08/hour-m, for butt welds, about 6E-09/hour-weld, for circumferential welds, about 6E-10/hour-m, and for plpe fittings, such as bends, etc., 1E-08/hour-fitting. These values are representative for small leakage of shop welds, taken from fuston studies and from the nuclear fission industry. Buende also gives multipliers to treat these fallure rates for different weld fallure modes and fabrication locations. Large leaks should be $0.1 \times$ the given rates. Weld ruptures should be $1 \mathrm{E}-02 \times$ the given rates. Maintenance welds should be $10 \times$ the given rates. Field welds should be $3.2 \times$ the given rates. This weld information ${ }^{5-18}$ is from the best discussion of weld reliability published in the last several years, and it is applicable to cryogentc 
system welds that are as important to safety and availability as blanket welds. I assume that leakage refers to leak rates less than $190 \mathrm{l} / \mathrm{min}$, and rupture refers to flows equal to the pipe's normal system flow rate.

\subsection{Expansion Engines}

These can be either reciprocating or turbomachine units, either gas handling or 1 iquid handling. Fermilab small helium reciprocating expanders had initial runs of only 1,000 hours duration due to broken drive shafts and bad seals. Runs lengthened to 1,300 hours between major equipment downtimes after the shafts were repaired and only the piston seals caused problems. Using new, Nitrile 0-rings for piston seals gave much better performance, up to 3,000 hours. ${ }^{5-19}$ This equipment break-in period lasted about two years. As we can see from the MTBF increase, the equipment failure rate dropped by a factor of 3 in that time. Therefore, the constant failure rate for a smal1, dry reciprocating gas expander is on the order of 3E-04/hour. The error factor is probably smaller than 10 for these actual data, perhaps 3 (good data) or 5 (medium cinfidence in the data) should be used instead. I suggest a factor of 3 for conservatism because the results are from a medium size set of 48 components.

Fermilab's small (95 liters/hour) reciprocating wet expanders showed MTBFs of 2,000 hours over the first 2 years of operation. This gives a failure rate of 5E-04/hour. Later improvements in wet reciprocating expander seals gave MTBFs of 4,200 hours, for a failure rate of 2E-04/hour. 5-19 Again, I suggest an error factor of 3.

Recent work on turbomachine reliability suggests that the axial flow turbomachines as a class perform much more reliably than their predecessors, the reciprocating piston units. Continuous duty run times of years between maintenance outages have been achieved, with strides as long as 10 years between major overhauls. ${ }^{5-20}$ Therefore, I suggest that a new fusion facility, needing large quantities of cryogens (thousands of liters per hour, or kilowatts of heat removal) for magnet cooling, should take advantage of newer, more reliable turbomachine technology. 
For axial. flow air and oxygen turbocompressors, failure rates of about 5E-05/hour are given in the 1iterature. ${ }^{5-11}$ For guidance, I consider this to be a conservative estimated failure rate for wet and dry cryogenic turboexpanders. An error factor of 10 is appropriate for these units, since no error factor is reported in reference 5-11. Typical repair times on the order of 18 hours were cited for this equipment:

\subsection{Heat Exchangers}

LN2 or LHe cryogenic heat exchangers can suffer from small inleakages of air, which freezes and begins to plug up flow in the units, as seen in LCT experiences discussed in Chapter 2. They can also suffer large leakages to the atmosphere or through the plates to the opposite fluid. LNG plate and fin heat exchanger experience gives a major failure rate of 6E-06/hour, and a minor failure rate of about 1E-05/hour. Major failures are those requiring over 24 hours of downtime, or else they are considered as major accidents. Minor failures require repair, blit keep the plant down less than 24 hours. ${ }^{5-12}$ These values are adequate to apply to other cryogenic heat exchangers because of similar design styles and also that the design choice of low temperature compatible materials has been performed. Error factors of 100 should be used with these values.

\subsection{Cryogenic Valves}

LNG valve experience with external leakage and freezing in an open position gives a failure rate of about $6 \mathrm{E}-07 /$ hour. Minor failures, typically small leaks, have a failure rate of $3 E-06 /$ hour. Both of these values have an error factor of $100 .^{5-12}$ I find these valve failure rates to be lower than I expected. Also, R. Callis $s^{5-21}$ of the DIII-D experiment has suggested that some of these valves can only be exercised perhaps 10 to 100 times before they significantly leak past the seat because of seat scarring and deterioration.

I suggest in this case that 1 ight water reactor valve information be used for these cryogenic components, since it will be conservative. Also, conservative values will be used to address the leak-past-the-seat

operating concerns. From fission experiences, motor operated valve 
failure rates are on the order of 1E-03/demand for failure to operate, and $1 E-04 /$ demand for plugging up (failing to remain open), with error factors of 3.5-13 Also for conservatism, I will use the 6E-07/hour for an external rupture failure rate from the LNG data, ${ }^{5-12}$ since it is a factor of 60 larger than the light water valve failure rate for that failure mode. The fission reactor value for check valve leakage past the seat is given as 3 E-07/operating hour, ${ }^{5-13}$ but due to the differences between actuated valves and the concerns over cryogenic valve seat durability, I suggest using 3E-03/operating hour for cryogenic service motor operated valve leakage past the seat. Pneumatic or air operated valve failure rates are on the order of 3E-04/demand for failure to operate, and the same values for plugging up, rupture, and leakage past the seat as given above. An error factor of 5 should be applied to these values. These valve failure rates are factors of 300 and higher than the LNG valve experience values, but are much more reasonable for order-of-magnitude data when one considers that the type of operations (number of demands, etc.) at a fission plant will be closer to a fusion cryogenic system than that of LNG facilities. Also, the LNG component failure experience report did suggest that the questionnaires might not have been filled out accurately for valves. ${ }^{5-12}$

Cryogenic overpressure relief valve failure to open rates from accelerator helium system experience are 1E-02/demand. ${ }^{5-22}$ I suggest an error factor of 5 for this value. Reasons for this high failure rate are that the valves would get plugged with foreign materials from the holium coolant in the magnet cases, from materials loose within the magnet cases, and valve faults. This is a good example of actual operations experience amending a failure rate. For example, a spring loaded safety relief valve failure rate for failing to open might be 1E-05/demand, and premature opening might be 1E-05/hour for a iight water reactor. ${ }^{5-13}$ I also assume relief valve body ruptures are about the same value as the LNG valve external leakage rate, at 6E-07/hour. That assumption is conservative, since relief valves are usually smaller than process valves and therefore have a somewhat smaller chance of material flaws included in them during manufacture. 


\subsection{Cryogenic Pumps}

The LNG study ${ }^{5-12}$ gave a major failure rate for centrifugal pumps of about 3E-04/hour, with most failures being in the bearings and the drive motors. I assume that this failure rate is in the fallure to run category. Failure to start on demand was not covered, since LNG facilities typically operate in a continuous manner. Therefore, I assume a fission reactor value for pump failure to start on demand on $3 E-03 /$ demand, with an error factor of 5. 5-23 LNG minor failures had a failure rate of about 2E-05/hour, which $I$ assumed meant running in off-normal parameters, typically underspeeding. I assume that pump casing breach failures have a failure rate of $1 \mathrm{E}-09 /$ hour, with an error factor of $30 .{ }^{5-24}$

\subsection{Pressurized Cryogenic Liquid Storage Tanks}

Failures of these large tanks can have great consequences, as discussed in Chapter 3 for the NASA storage tank failure that released $2,755 \mathrm{~m}^{3}$ of LOx. Storage tanks for LNG and LPG have been examined for their accident consequences, and will be discussed in the next chapter. Briefly, the breach failure rates appear to be on the order of 1E.06 to 1E-07/year. ${ }^{5-25}$ These very low failure rates are intended to indicate that there is very low risk from the storage tanks. Indeed, with concrete bund walls and some tanks themselves being made of cryogenically stable concrete, they are very solid structures, capable of withstanding normal operational events, such as overpressure. For earthquakes, a large storage tank breach failure rate of $1 \mathrm{E}-04$ /year is suggested. ${ }^{5-25}$ If a fusion facility storage tank is made of concrete and protected as these tanks are, then these LNG tank failure rates should apply to the fusion tanks.

\subsection{Cryogenic Instrumentation}

Typical instruments for cryogenic systems are liquid level indicators, general pressure transducers, venturi gauges for flow measurement, silicon diode temperature detectors, and cold cathode gauges for vacuum measurement. ${ }^{5-26}$ I rely on NASA Saturn rocket part experiences for 
some of these failure rates. ${ }^{5-27}$ Using the failure rate modifiers for liquid helium temperatures, liquid level sensor failure rates are: incorrect output, 2E-03/hour; no output, 6E-04/hour; and erratic indication, 4E-05/hour. These values have an error factor of 2. Pressure transducer failure rates are: low output, 8E-03/hour; high output, 7E-03/hour; erratic output, 6E-03/hour; and external leakage, 7E-04/hour. Again, these values have an error factor of 2. Turning to other data sources, flow-indicator controllers for an ammonia plant have a failure rate of 2.5E-01/year (and we can assume year round operation, or about $3 E-05 /$ hour)..$^{5-28}$ In comparison generic failure rate data for al1 types of flow measurement devices is 6E-06/hour (reference 5-12, page 573). I suggest using 1E-05/hour with an error factor of 10 to account for possible venturi plugging and any low temperature effects in the instrument. I anticipate that silicon diode temperature detectors will have operational problems due to impurities in the flow stream, such as metal shavings, noncondensible gases, etc. Typical silicon diode failure rates are on the order of $1 \mathrm{E}-06 /$ hour for short circuits, intermittent circuits, and open circuits. ${ }^{5-29}$ To account for the rest of the instrument and the low temperature effects, I suggest a failure rate of $1 \mathrm{E}-05 /$ hour with an error factor of 10 . Cold cathode gauges, or Penning gauges, are rather simple devices. They consist of anode and cathode arranged in a low strength permanent magnet field. ${ }^{5-30}$ such simple meters should not have many failure modes, and should be reliable. of course, these gauges cannot be used near the fringe field from the fusion magnets. I suggest a failure rate of 1E-03/year for these gauges, since this failure rate is the mid-point of the range of events commonly regarded as unlikely events. For a continuously operating unit (as we would find in a cryogenic system because significant downtimes are realized when warming and cooling the system) the failure rate would be about 1E-07/operating hour. I also assume a conservative error factor of 10 for the cold cathode gauge failure rate.

\subsection{Gas Handling Plant Equipment}

The warm gas handling subsystem duplicates some of the same equipment from the cryogenic temperature side of the plant, namely compressors and storage tanks. Another component to consider here is the gas storage 
cylinder. These steel cylinders generally have a 24 year imposed Iffe, to keep wall thinning from creep due to pressure loads and internal corrosion problems from causing a breach event. ${ }^{5-31}$ If we consider that these cylinders are maintained we11, cleaned regularly, and handled carefully, then the assumption of no failure over service life is reasonable. Therefore, using a $50 \%$ Chi-Square distribution ${ }^{5-17}$ on zero fallures and 24 operating years give $0.455 / 2$ (24 years) $=9.5 \mathrm{E}-03 /$ year, or about 1E-02/year. A 95\% upper Entund failure rate would be $3.841 / 2(24$ years) = $8 \mathrm{E}-02 /$ year.

Other warm gas handling plant component failure rates have been taken from the literature on natural gas, and ammonia facilities. While these failure rates are not from the exact same equipment, they are from the correct industrial application of gas handling, and serve in analogou. functions in their respective plants. These failure rates are indicalive enough for our fusion facility order-of-magnitude analyses. The warm gas plant component failure rates are given in Table 5-1.

\subsection{Unpressurized Storage Containers}

Small 'dewar' cryogenic storage containers are simply unpressurized, insulated containers to limit the amount of heat inleakage boiloff. Larger cryogenic containers, usually referred to as cryostats, generally utilize pressure to suppress boiling. The cryostat containers are actually only as good as their ability to maintain an effective vacuum insulation space. Once that space is filled with either the cryogen or air, heat transfer into the inner vessel increases and boiling can no longer be suppressed. Therefore, since failure of either the inner or outer wall will fail the unit, the failure rate for either the inner chamber or the outer chamber (whichever is larger) is used for the entire cryostat.

For dewars, Tantam ${ }^{5-34}$ states that the vacuum space between chambers lasts 7 years or perhaps longer. If we consider that these dewars are well cleaned and maintained, do not form ice plugs, are not abused, etc., then a $50 \%$ Chi-square distribution failure rate with zero faults in seven years is $0.455 / 2$ (7 years) $=3 E-02 /$ year. The $95 \%$ upper 
Error

Component Description

Eailure rate factor Reference

Gas-operated shutoff valve,

$0.2 /$ year

3

$5 \cdot 32$

fail to operate

Turbine flow meter (reads high or low)

$0.06 /$ year

3

$5-32$

Resistance temperature detector

$0.07 /$ year

3

$5-32$

(reads high or low)

Pressure transmitter (reads high or low)

$0.2 /$ year

3

$5-32$

Gas density meter (reads inigh or low)

$0.06 /$ year

3

$5-32$

Process control computer system

$100 /$ year

3

5-32

fail to operate

Gas compressor (assumed to be turbo unit)

$5 E-03 /$ hour

$5-32$

fail to operate

Solenoid valve, fail to sperate

$5 E-02 /$ year

5

5- 28

Control valve, fail to operate

$3 E-02 /$ year

5

5-28

Uninterruptible power supply system

$3 E-02 /$ year

$5-28$

fail to operate

Large compressor, fail to operate

$5 E-02 /$ year

5

$5-28$

(assumed to be turbo unit)

Gas Piping, all diameters, catastrophic

$2 \mathrm{E}-11 / \mathrm{hr}-\mathrm{m}$

4

$5-33$

failure (taken from natural gas pipe data)

Piping connection leakage

$6 E-07 /$ hour

$5-33$ 
bound fatlure rate is $3.841 / 2$ (7 years) is about $3 \mathrm{E}-01 /$ year. Considering some of the abuse that these dewars survive when subjected to rigorous testing, this is a conservative failure rate..$^{5-35}$

For large metal cryostats, I assume that they are built simtlar to low temperature, unftred pressure vessels used in the chemical industry. A reliability survey of these and other thin walled, unfired pressure vesse1 $\mathrm{s}^{5-36}$ shows that an average failure rate for breaches is 1E-03/year, under normal service conditions. An error factor of 4 applifes to this failure rate. Seismic responses must be judged separately. If the cryogenic cryostat has many penetrations, such as those with flexible bellows, then the fallure rate of penetrations must be assessed. Also, if the cryostat is not thick walled or robust enough to handle small pressure transients, then the 1E-03/year value may be too 1 iberal.

Large, thick-walled concrete cryostats, are very similar to the LNG storage tanks mentioned in section 5.7. Therefore, an order-of-magnitude breach failure rate for such a tank in a fuston facility is probably 1E-06/year, without consideration of seismic, impact, or crane operations induced fallures.

Table 5-2 gives a summary of the failure rates cited in this chapter for cryogenic components. These failure rates can be used for fusion cryogenic system risk assessment, reliability analysis, design trade-off studies, and availability analyses. ible 5-3 gives some average hands-on component repair times from the referenced accelerator discussions and other data sources. 
TABLE 5-2, SUMMARY OF ORDER-OF -MAGNITUDE FAILURE RATES FOR CRYOGENIC SYSTEM COMPONENTS APPLICABLE TO FUSION FACILITIES Component Description

Failure Rate Error Factor

Small reciprocating compressor

all fallure modes 3E-03/hour

Large reciprocating compressor

all fallure modes

$5 E-05 /$ hour

100

Large turbo-compressor

all fallure modes

$1 E \cdots 04 /$ hour

10

Smal1, dry reciprocating gas expander

all fallure modes

3E..04/hour

Sma11, wet reciprocating expander

all fallure modes

$2 E-04 /$ hour

3

Axial flow turbo-compressor

$5 E-05 /$ hour

10

all fallure modes

Plate and fin heat exchanger

major failures (breach)

$6 E-06 /$ hour

100

minor failures (leakage)

1E-05/hour

100

Motor-operated valve (all sizes)

fails to operate on demand

$1 E-03 /$ demand

3

plugging

$1 E-04 /$ demand

external rupture

$6 E-07 /$ hour

5

leak past the seat

$3 E-03 /$ hour

5

freezing up in position

6E-07/hour

100

Air-operated valve (all sizes)

fails to operate on demand

$3 E-04 /$ demand 3

plugging

$1 E-04 /$ demand

3

external rupture

$6 \mathrm{E}-07 /$ hour

5

leak past the seat

$3 E-03 /$ hour 
TABLE 5-2. SUMMARY OF ORDER-OF-MAGNITUDE FAILURE RATES FOR CRYOGENIC SYSTEM COMPONENTS APPLICABLE TO FUSION FACILITIES (Cont inued)

Pressure relief valve (all sizes)

fail to open on demand

$1 E-02 /$ demand

5

external rupture

$6 E-07 /$ hour

5

premature opening

$1 E-05 /$ hour

3

Motor-driven centrifugal pump (a11 sizes)

fall to continue to run

$3 E-04 /$ hour

100

fail to start on demand

$3 E-03 /$ demand

5

fail to run at rated speed

2E-05/hour

100

external breach fallure

$1 E-09 /$ hour

30

Large cryogenic storage tank breach

$1 E-06 /$ year

Liquid level sensor

incorrect output

no output

erratic indication

2E-03/hour

2

$6 E-04 /$ hour

2

$4 E-05 /$ hour

2

Pressure transducer

low output

8E-03/hour

2

high output

7E-03/hour

2

erratic output

$6 \mathrm{E}-03 /$ hour

2

external leakage

7E-04/hour

2

Venturi flow meter, all modes

$1 E-0$ s/hour

10

Silicon diode temperature detector

all failure modes

1 E-05/hour

10

Cold cathode vacuum gauge

all failure modes

$1 E-07 /$ hour

10

Steel gas cylinder breach

$1 E-02 /$ year

8 
TABLE 5-2. SUMMARY OF ORDER-OF-MAGNITUDE FAILURE RATES FOR CRYOGENIC SYSTEM COMPONENTS APPLICABLE TO FUSION FACILITIES (Cont inued) Component Description Fallure Rate Error Factor

Insulated dewar botls dry $3 E-02 /$ year

Metal cryostat inner or outer 1E. $-03 /$ year shell breach

Concrete cryostat breach

$1 E-06 /$ year

Cryogenic pipe (all diameters) breaches

$5 E-09 /$ hour $-m$ 100

leakage $6 E-10 /$ hour $-m$ 100

Metal bellows breach failure $3 E-05 /$ demand 10 (based on 7000 operating cycles)

Weld, small leakage fallure Longitudinal weld $6 E-08 /$ hour $-m \quad 5$ Butt weld 6E-09/hour-m 5

Circumferential weld $6 E-10 /$ hour-weld 5

Pipe fitting weld 1E-08/hour-fitting 5

Note: gas handling plant component fallure rates are given in Table 5-1 Weld multipliers: large leak fatlure rate is $0.1 \times$ given values, field weld fallure rates should be $3.16 \times$ given values, and maintenance welds should be $10 \times$ given values. Weld ruptures should be $1 \mathrm{E}-02 \times$ the given values. I estimate that small leaks can range from drops per minute to $5 \%$ of plpe flow, or $1901 / \mathrm{min}$, whichever is larger. Large leaks likely range from $5 \%$ up to $50 \%$ of pipe flow, and ruptures are taken to be $100 \%$ of pipe flow. 
TABLE 5-3. TYPICAL HANDS-ON COMPONENT REPAIR TIMES FOR CRYOGENIC COMPONENTS WITH APPLICABILITY TO FUSION FACILITIES

Equipment t tem to be repatred

Sma11 cold box

(warmup, entry, and cooldown)

Cryogentc transfer 1 ine

wet reciprocating expander

dry reciprocating expander

Plug leaky heat exchanger $u$-tube

Compressor

Recovery from a gas

explosion in a compressor

Air compressor
Repair time, hours Reference

146

$5-10$

1

5- 10

1

$5-10$

1

$5-10$

0.1

5- 10

60

5- 10

3 to 6 days

$5-12$

18

5-11 
5-1. D. Kececloglu, Rellabllity Engineering Handbook, volume 1 , Prentice Hall, Inc., Englewood Cliffs, NJ, 1991, pages 72-77.

5-2. C. M. Ryerson, "The Reltabllity Bathtub Curve is Vigorousiy Alive, "Proceedings of the Annual Rellability and Maintainability Symposium, Los Angeles, CA, January 26-28, 1982, pages 313-316.

5-3. PRA Procedures Gutde. A Gutde to the Performance of Probabilistic Risk Assessments for Nuclear Power Plants, NUREG/CR-2300, US Nuclear Regulatory Commisston, January 1983, pages 3-99 to 3-106.

5-4. R. L. Dennig et a1., Operating Expertence Feedback Report - New Plants (Commercial Power Reactors), NUREG-1275, US Nuclear Regulatory Commisston, July 1987.

5-5. "The IEA Large Coll Task, Descrlption of the Factlity and Its Operation," Fuston Engineering and Destan, I, September 1988, pages 89-93.

5-6. R. F. Barron, Cryogentc Systems, Oxford University Press, NY, 1985, Chapter 3.

5-7. H. P. Bloch and F. K. Gettner, Major Process Equipment Maintenance and Repair, Gulf Publishing Company, Houston, TX, 1985, pages 420-447.

5-8. H. Springmann, "Cryogenics Principles and Applications, "Chemical Enqineering, 92, May 1985, pages 58-67.

5-9. R. A. Andrews et a1., "Helium Refrigeration system and Cryogentc system for Superconducting Switchyard Magnets at Fermilab, "IEEE Iransactions on Nuclear Sctence, NS-26, June 1979, pages 4093-4095.

5-10. P. D. Brindza et a1., "Energy Doubler Refrigeration System," IEEE Transactions on Nuclear Sctence, NS-26, June 1979, pages $4102-4104$.

5-11. IEEE Guide to the Collection and Presentation of Electrical, Electronic, Sensing Component, and Mechanical Equipment Rel lability Data for Nuclear-Power Generating Stations, IEEE Std 500-1984, New York: Institute of ETectrical and Electronics Engineers, December 1983. (Note: specific values surveyed from pages 1239 to 1248)

5-12. L.W. Johnson and J.R. Welker, Development of an Improved LNG Plant Failure Rate Data Base, PB82-153503, Applied Technology Corporation, Norman, OK, September 1981. Prepared for the Gas Research Institute. Avallable through NTIS. 
5:13. N. C. Rasmussen et a1., Reactor Safety Study - An Assessment of Accident Risks in U.S. Commerc lal Nuclear Power Plants, WASH-1400, NUREG-75/014, US Nuclear Regulatory Commisston, October 1975, Appendix III, "Fallure Rate Data".

5-14. R. E. Wright et a1., Plpe Break Froquency Est imation for Nuclear Power Plants, NUREG/CR-4407, EGG-2421, EG\&G Idaho, Inc, May 1987.

5-15. H. M. Thomas, "Pipe and Pressure Vessel Fatlure Probabiltty," Reliabllity Engineering, 2, 1981, pages 83-124.

5-16. E. A. Merrick et a1., "Repatr of Bellows Expansion Joints," ASME Journal of Pressure Vessel Technology, 105, February 1983, page: $80-84$.

5-17. E. L. Welker and M. Lipow, "Esttmating the Exponential Fallure Rate from Data with No Fallure Events," Proceedings of the 1974 Annual Reliability and Maintainabllity symposium, IEEE Catalog No. 74CH08201ROC, Los Angeles, CA, January 29-31, 1974, pages $420-27$.

5-18. R. Buende et al., "Rel labllity of Welds and Brazed Joints in Blankets and Its Influence on Avallabilits," presented at the Second International Sympostum on Fusion Nuclear Technology, June 2-7, 1991, Karlsruhe, Germany.

5-19. C. H. Rode et a1., "Operation of Large Cryogenic Systems, "IEEE Iransactions on Nuclear Science, NS-32, October 1985, pages 3557-3561.

5-20. C. Jackson and $W$. Wolentarski, "Factors Affecting Turbomachinery Reliablitty, "Cryogentc Processes and Equipment - 1989, The Seventh Intersoctety Cryogentcs Symposium, American Society of Mechanical Engineers, 1989.

5-21. R. Callis, GA Technologles, Review Panel comment during Burning Plasma Experiment Conceptual Design Review for the cryogenic cooling system, March 26, 1991.

5-22. C. H. Rode et a1., "Operation of the TEVATRON Satellite Refrigerators for 0.75 -and 2.0-k 1 lometer-long Magnet Strings," IEFE Transactions on Nuclear Science, NS-30, August 1983, pages $2892-2894$.

5-23. S. A. Eide et al., Generic Component Failure Data Base for Light Water and Liquid Sodium Reactor PRAS, EGG-SSRE-8875, EG\&G Idaho, Inc., February 1990.

5-24. S. A. Eide et a1, Component External Leakage and Rupture Frequency Est imates, EGG-SRE-9639, EG\&G Idaho, Inc., November 1991 .

5-25. M. J. Elliott, "Use of quant ified risk assessment techniques in relation to major hazard installations, "Cryogenics, 28, December 1988, pages 835-837. 
5-26. W. E. Cooper et a1., "Cryogenic System for Production Testing and Measurement of Fermilab Energy Saver Superconducting Magnets," IEEE Transactions on Nuclear Science, NS-30, August 1983, pages $3602-3604$.

5-27. Saturn Component Failure Rates and Failure Rate Modifiers, NASA Technical Memorandum, NASA TM X-64619, Quality and Reliability Assurance Laboratory, Marshall Space Flight Center, 1971.

5-28. J. Prijate1, "Failure Analys is of Ammonia Plant Shutdown Instrumentation and Contro1," Plant/Operations Progress, $\underline{3}$, January 1984, pages 25-28.

5-29. N. B. Fuqua, Reliability Engineering for Electronic Design, Marcel Dekker, Inc., New York, 1987, pages 172-173.

5-30. J. F. O'Hanion, A User's Guide to Vacuum Technology, John Wiley \& Sons, Inc. New York, 1980, pages 68-69.

5-31. Standard for Requalification of DOT-3HT Seamless Steel Cylinders, CGA C-8, Compressed Gas Association, 1985.

5-32. H. Lammerse and M. Bosman, "Data of Gas Compressors and Instrumentation - Hard to Collect, Easy to Analyse," Reliability Engineering, 13, 1985, pages 65-78.

5-33. Guidelines for Process Equipment Reliability Data with data tables, Center for Chemical Process Safety, American Institute of Chemical Engineers, 1989, pages 183-184.

5-34. D. Tantam, "Applications of cryogenic containers," Cryogenics, 21, December 1981, pages 691-695.

5-35. W. Shattes, "Design and Use of Containers for Cryogenic Liquids," Plant/Operations Progress, 5, January 1986, pages 17-22.

5-36. D. C. Arulanantham and F. P. Lees, "Some Data on the Reliability of Pressure Equipment in the Chemical Plant Environment," International Journal of Pressure Vessels and Piping, 9, 1981, pages $327-338$. 
6. Cryogenic System Initiating Events for Fusion Facilities

This chapter gives a summary of published risk assessment initiating event (IE) frequency information relating to cryogenic systems. This information is from superconducting magnet cooling system safety assessments and safety analyses performed for other industries. Chapter 5 gave suggested component failure rates for analysts to use when building IE fault trees. IEs are the initial failure events that lead to an undesired system or facility condition, such as release of radioactive materials or destructive release of energy. As in other chapters, other industry information, such as that from liquefied natural gas (LNG), liquefied ammonia, and liquefied petroleum gas facilities (LPG), has been reviewed along with magnetic fusion safety work to compile the information discussed here.

These frequencies can be used as initial numbers in a scoping study of the risks from possible hazards. IE frequencies for large scale industrial operations should be larger than those for a fusion facility's more modest operations. A large LNG facility might handle 100 to 1,000 tons/day, while a fusion facility might handle quantities up to 100 tons of LHe/day. Fusion LHe systems will be operated more in the refrigerating mode, removing kilowatts of heat from the magnets (without continuous liquefication). A fusion facility's LN2 needs are likely to be higher than LHe, but also in the heat removal mode. The LN2 might be allowed to boil and be re-liquefied. Later, when detailed safety work is done for fusion, the initiating event values given here can be used for comparison to the calculated IE frequencies, to provide a check against other, independent work from other industries.

Table 6-1 gives order-of-magnitude IE frequencies reported in the literature. These values can be used for fusion facilities. I have assumed that the variety of cryogenic systems are similar enough in design to fusion facilities that the IE values reported for these different industries will be indicative of conservative frequency magnitudes for fusion facilities. All industries using cryogenic fluids need to take similar design precautions, such as retarding heat transfer into the fluid by insulation and optimized pipe design. Cryogen transfers to trucks or raii cars will also likely be similar for all facilities, except for the 
Initiating Event Description

Large LHe magnet coolant loss-of-coolant accident

Loss of fusion magnet insulating vacuum

Cryogen terminal spills and incorrect transfers (assume error factor of 10)

\section{Frequency Reference}

$1 E-04 / y r \quad 6-1$

$3 E-03 / y r \quad 6-2$

$1 E-06 / y r \quad 6-3$

to

$1 \mathrm{E}-07 / \mathrm{yr}$

$1 E-07 / y r \quad 6-4$

$1 E-10 / y r \quad 6-4$

$1 E-15 / y r \quad 6-4$

to vacuum creation inside tank

Inadvertent yaseous release from rail car

during unloading (assume 1500 cars/year)

1E-06/car $\quad 6-5$

Driver moves cryogen truck while it is still connected to unloading arm, following completion of unloading, a large release results (assume 1000 trucks/year)

$1 E-04 /$ truck $6-5$

Cryogen release from truck unloading arm if truck shifts position while still connected (medium release, 1000 trucks/year)
IE-05/truck $6-5$ 
TABLE 6-1. CRYOGENIC SYSTEM INITIATING EVENT FREQUENCIES FROM

Initiating Event Description

Refrigerated cryogen storage tank farm failures

from events within the plant
Frequency Reference

$1 E-06 / y r \quad 6-6$

to

$1 \mathrm{E}-07 / \mathrm{yr}$

Refrigerated cryogen storage tank farm failures

from events outside of the plant (earthquake, etc.) 1E-04/yr 6-6

Storage tank farm events (for 18 tanks)

drainage spill, not following procedure

Tank overfilling

Tank instrument connection breakage

cryogen leakage from flanged joint

cryogen leakage from pump sea?

US cryogen spill incidents

cryogen plant small fires

cryogen truck loading and unloading spills

(truck value estimated from a Chi-square

distribution on zero large failures)

cryogen nipework failure (over whole refinery)

cryogen tank serious fatigue failure

cryogen tank overpressurization by overfilling

cryogen tank car derailment

probability of overturning, given derailment

Tank truck road accident involving spill
$5 E-03 / y r \quad 6-7$

$1 E-01 / y r \quad 6-7$

$1 \mathrm{E}-04 / \mathrm{yr} \quad 6-7$

$1 \mathrm{E}-02 / \mathrm{yr} \quad 6-7$

$2 \mathrm{E}-02 / \mathrm{yr} \quad 6-7$

$1 E-05 / h r \quad 6-8$

$4 E-06 / h r \quad 6-8$

$2 \mathrm{E}-07 / \mathrm{hr} \quad 6-8$
$5 E-03 / y r \quad 6-9$

$2 E-04 / y r \quad 6-9$

$1 E-04 / y r \quad 6-9$

$1 \mathrm{E}-06 / \mathrm{km} \quad 6-9$

$0.2 \quad 6-9$

$2 E-08 / \mathrm{km} \quad 6-9$ 
wide variance in the number of transfers per year. Error bounds are not typically reported, since these values should be conservative upper bounds.

Some of the IE frequencies given in Table 6-1 are very low. Frequencies on the order of 1E-10/year are not credible values. Such low frequencies are meaningless, unless the authors are trying an indirect means to illustrate that concern is not necessary for the particular event. I suggest stating such facts in the text, not by using an extremely low value. Such low frequencies are not meaningful and can damage the credibility of the entire analysis.

A failure modes and effects analysis for an MHD experiment gave some qualitative initiating events. These were loss of insulating vacuum, failure of relief valves to open on overpressure (causing burst disks to open and risking an explosion due to liquid oxygen condensation), refrigerating shield overfill, pipe rupture, and high pressure gas explosions. ${ }^{6-10}$

Other events I noted in Chapter 3 that should be considered for inclusion as IEs are ozone explosions, control system errors, and human errors. Since attention has been given to ozone explosions, and reasons for their occurrence are known, I assume that these events can only occur with a low frequency at future fusion facilities. I will set a point estimate IE frequency of 1E-03/year, with an error factor of 10 , on ozone explosion events, since that is the midpoint of the probability range generally thought of as unlikely events.

I noted small discussions of control system errors and problems in the literature. Fermilab experiences showed that large cryoplant control systems could cause about 10-15 hours of downtime per month, 6-12 and LNG terminal experiences showed computer control system outage frequencies of $100 /$ year. $6-13$

Human errors in LHe cryoplant operations have also been noted at Fermilab. ${ }^{6-12}$ These were said to account for a few hours of system downtime eacin month. As a first attempt at estimating human error 
probabilities, I refer to the Systematic Human Action Reliability Procedure (SHARP). ${ }^{6-14}$ This procedure gives coarse estimates, usually overestimates, of human reliability for a variety of tasks, accounting for the task difficulty. SHARP estimates are usually very conservative, but they suffice until such time as detailed human factors Task Analysis can be performed using operator interviews, operating procedure reviews, and other similar information. For a new system, I assume a SHARP 'rule based' midrange error rate of 1E-02/demand for unusual actions where the operator might place the system in a detrimental condition. As the operators familiarize themselves with the system, this value should be reduced to a SHARP 'skill based' midrange error rate of 1E-03/demand. I assume that operator errors which can place the cryoplant in jeopardy will be blocked by the computer interlock system, but, since it could also fail, I assume a conservative IE frequency of 1E-02/year for operator errors harmful to the cryoplant. Maintenance errors should be discovered by system checks or tests prior to returning the system to operation, so I will assume an IE frequency of 1E-03/year for significant maintenance errors. These maintenance errors are those that endanger the system, such as allowing system breaches to the building to occur. 
6-1. R. Caporali et a1., "Safety Analys is of NET Magnet System," Fusion Technology 1990, Proceedings of the 16th Symposium on Fusion Technology, London, United Kingdom, September 3-7, 1990, pages 1417-1421.

6-2. R. Caporali, F. Tarisciotti, and S. Ciattaglia, "Safety Analysis of NET Magnet System: LIVA Accident," presented at the 14th IEEE Symposium on Fusion Engineering, San Diego, CA, September 29-0ctober 3, 1991 .

6-3. L. L. Philipson, "LNG Operations Risk Analyses: Evaluation and Comparison of Techniques and Results," Synthes is and Anaiys is Methods for Safety and Reliability Studies, Plenum Press, New York, 1980, pages 401-407.

6-4. F. Al-Abdulally et al., "Hazard Analys is and Safety Considerations in Refrigerated Ammonia Storage Tanks," Plant/Operations Progress, $\underline{6}$, April 1987, pages 84-88.

6-5. J. Prijatel, "Accidental Venting of Liquid Ammonia," Plant/Operations Progress, 2, April 1983, pages 131-136.

6-6. M. J. Elliott, "Use of quantified risk assessment techniques on relation to major hazard installations, " Cryogenics, 28, December 1980 , pages 835-837.

6-7. A. Mazzocchi et a1. "Risk Analysis of a Large Tank farm of Liquefied Petroleum Gases, "Reliability Data and Use in Risk and Availability Assessment, Proceedings of the 5th EUREDATA Conference, Heidelberg, Germany, April 9-11, 1986, Springer-Verlag, Berlin, 1986, pages 344-356.

6-8. D. W. Johnson and J. R. Welker, Development of an Improved LNG Plant Failure Rate Data Base, PB82-153503, Applied Technology Corporation, Norman, OK, September 1981. Prepared for the Gas Research Institute. Available through NTIS.

6-9. F. P. Lees, Loss Prevention in the Process Industries, Volume 2, Butterworths, London, 1980, Appendix 10, 'Canvey'.

6-10. L. R. Turner et al., "Safety Analys is of the UTSI-CFFF Superconducting Magnet," Advances in Cryogenic Engineering, 25, 1979, paper A-5, pages 39-48.

6-11. R. C. Niemann et a1., "Cryogenic Design of the CFFF Superconducting Magnet System for MHD Research," Cryogenic Processes and Equipment in Energy Systems, American Society of Mechanical Engineers, 1980, pages 175-180.

6-12. C. H. Rode et al., "Operation of Large Cryogenic Systers," IEEE Transactions on Nuclear Science, NS-32, October 1985, pages 3557-3561. 
6-13. H. Lammerse and M. Bosman, "Data of Gas Compressors and Instrumentation - Hard to Collect, Easy to Analyse," Reliability Engineering, 13, 1985, pages 65-78.

6-14. G. W. Hannaman et al., Systematic Human Action Reliability Procedure (SHARP), EPRI NP-3583, Electric Power Research Institute, June 1984. 

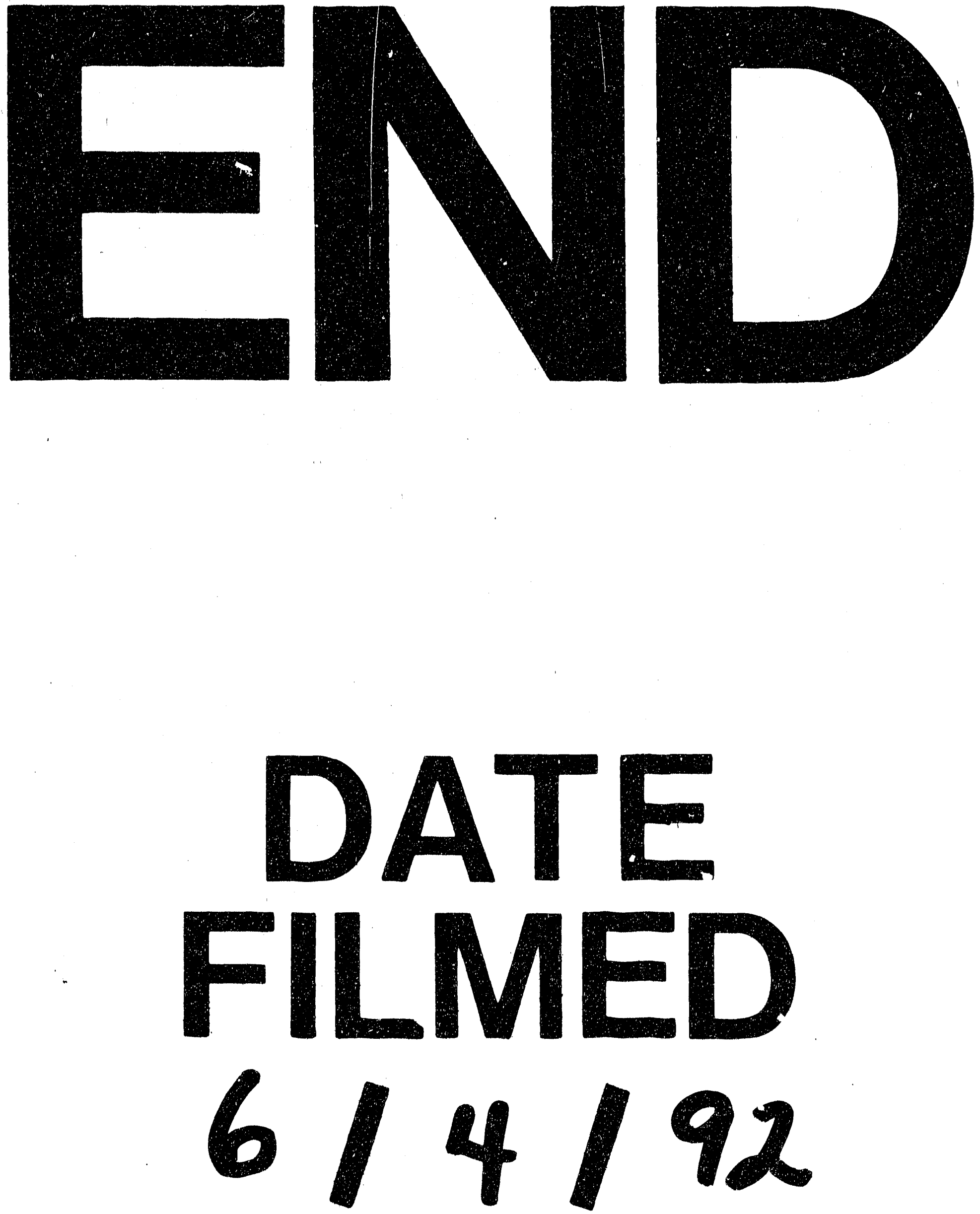
